\title{
Doxorubicin triggers bioenergetic failure and p53 activation in mouse stem cell-derived cardiomyocytes
}

\author{
Teresa Cunha-Oliveira $^{\mathrm{a}, *, 1}$, Luciana L. Ferreira ${ }^{\mathrm{a}, 1}$, Ana Raquel Coelho ${ }^{\mathrm{a}, \mathrm{b}}$, Cláudia M. Deus ${ }^{\mathrm{a}, \mathrm{b}}$, \\ Paulo J. Oliveira ${ }^{\mathrm{a}, \mathrm{b}}$ \\ ${ }^{\text {a }}$ CNC, Center for Neuroscience and Cell Biology, University of Coimbra, UC-Biotech Building, Biocant Park, Cantanhede, Portugal \\ ${ }^{\mathrm{b}}$ Institute for Interdisciplinary Research (I.I.I.), University of Coimbra, 3030-789 Coimbra, Portugal
}

\section{A R T I C L E I N F O}

\section{Keywords:}

Doxorubicin

Cardiotoxicity

Mitochondria

Pyruvate Dehydrogenase (PDH)

Apoptosis

Cancer chemotherapy

\begin{abstract}
A B S T R A C T
Doxorubicin (DOX) is a widely used anticancer drug that could be even more effective if its clinical dosage was not limited because of delayed cardiotoxicity. Beating stem cell-derived cardiomyocytes are a preferred in vitro model to further uncover the mechanisms of DOX-induced cardiotoxicity. Our objective was to use cultured induced-pluripotent stem cell(iPSC)-derived mouse cardiomyocytes (Cor.At) to investigate the effects of DOX on cell and mitochondrial metabolism, as well as on stress responses.

Non-proliferating and beating Cor.At cells were treated with 0.5 or $1 \mu \mathrm{M} \mathrm{DOX}$ for $24 \mathrm{~h}$, and morphological, functional and biochemical changes associated with mitochondrial bioenergetics, DNA-damage response and apoptosis were measured. Both DOX concentrations decreased ATP levels and SOD2 protein levels and induced p53-dependent caspase activation. However, differential effects were observed for the two DOX concentrations. The highest concentration induced a high degree of apoptosis, with increased nuclear apoptotic morphology, PARP-1 cleavage and decrease of some OXPHOS protein subunits. At the lowest concentration, DOX increased the expression of p53 target transcripts associated with mitochondria-dependent apoptosis and decreased transcripts related with DNA-damage response and glycolysis. Interestingly, cells treated with $0.5 \mu \mathrm{M}$ DOX presented an increase in PDK4 transcript levels, accompanied by an increase in phospho-PDH and decreased PDH activity. This was accompanied by an apparent decrease in basal and maximal oxygen consumption rates (OCR) and in basal extracellular acidification rate (ECAR). Cells pre-treated with the PDK inhibitor dichloroacetate (DCA), with the aim of restoring PDH activity, partially recovered OCR and ECAR.

The results suggest that the higher DOX concentration mainly induces p53-dependent apoptosis, whereas for the lower DOX concentration the cardiotoxic effects involve bioenergetic failure, unveiling PDH as a possible therapeutic target to decrease DOX cardiotoxicity.
\end{abstract}

\section{Introduction}

Doxorubicin (DOX) is a widely used anticancer drug that causes DNA damage by intercalating into DNA and by inhibiting topoisomerase II, resulting in disruption of gene transcription, inhibition of cancer cell proliferation, and apoptosis (Minotti et al., 2004). Despite its antineoplastic efficacy, DOX dosages used in the clinic are limited by their adverse effects including a dose-dependent, cumulative and delayed cardiotoxicity (Carvalho et al., 2014). Uncovering all molecular mechanisms involved in DOX cardiotoxicity may help to design strategies to prevent these critical side-effects of cancer chemotherapy. The cellular and molecular mechanisms associated with DOX cardiotoxicity include oxidative stress, resulting from DOX redox cycling mediated by mitochondrial complex I (Davies and Doroshow, 1986; Oliveira et al., 2004; Pereira et al., 2012). DOX-induced cardiomyocyte cell death has been shown to involve mitochondria-dependent apoptosis (Oliveira and Wallace, 2006; Sardao et al., 2009a; Ascensao et al., 2011; Deus et al., 2015) that may involve caspase-dependent (Sardao et al., 2009a; Ascensao et al., 2011; Deus et al., 2015) or -independent mechanisms mediated by the release of the apoptosis inducing factor (AIF) (Moreira et al., 2014). DOX treatment in rats also resulted in a decrease in adenine nucleotide transporter (ANT) protein content in cardiac tissue, increased susceptibility to mitochondrial permeability transition pore opening and inhibition of mitochondrial respiration (Solem and

\footnotetext{
* Corresponding author at: MitoXT (Mitochondrial Toxicology and Experimental Therapeutics Laboratory), CNC, Center for Neuroscience and Cell Biology, UC Biotech Building (Lote 8A), Biocant Park, 3060-197 Cantanhede, Portugal.

E-mail address: teresa.oliveira@uc-biotech.pt (T. Cunha-Oliveira).

${ }^{1}$ Authors contributed equally.
} 
Wallace, 1993; Zhou et al., 2001), most likely due to loss of cytochrome $c$ and cardiolipin (Pereira et al., 2016).

DOX treatment increased mitochondrial superoxide dismutase (SOD2) activity along with decreased activity of mitochondrial chain complexes I and V and activation of caspases 3 and 9 in cardiac tissue (Ascensao et al., 2011). In mice, a single DOX injection led to decreased cardiac function, increased cardiomyocyte apoptosis and decreased glucose and adenosine triphosphate (ATP) levels (Wei et al., 2015).

Some studies suggested that DOX-induced nuclear DNA damage in cardiomyocytes may be a primary cause of mitochondrial dysfunction (Sardao et al., 2009a), through the activation of p53. Up-regulation of p53 was found in H9c2 cells after treatment with DOX (Sardao et al., 2009a; Branco et al., 2012; Moreira et al., 2014; Deus et al., 2015). Active p53 may be located in the nucleus following DNA-damage response, but it may also translocate to mitochondria, leading to mtDNA repair or to outer membrane permeabilization, which culminates in mitochondrial-mediated apoptosis (Bakhanashvili et al., 2008; Vaseva and Moll, 2009). These mechanisms may rely on, or be responsible for, DOX-induced changes in gene expression (Pereira et al., 2016), since some p53 target genes encode proteins that regulate mitochondrial outer membrane permeabilization, such as the pro-apoptotic proteins Bax, Noxa and Puma (Vega-Naredo et al., 2015).

Most of our and others previous studies aimed at elucidating in vitro mechanisms behind DOX cardiotoxicity relied on the H9c2 cell line as a biological model (Sardao et al., 2009a,b; Branco et al., 2012; Li et al., 2013; Moreira et al., 2014; Cheung et al., 2015; Deus et al., 2015; Gergely et al., 2015; Lou et al., 2015; Coelho et al., 2017). However, this cell line has several limitations that can be overcome by using stem cell-derived cardiomyocyte cultures that maintain the capacity to beat in culture, which is relevant for cardiotoxic studies since cardiomyocyte contractility is highly dependent on cellular ATP levels (Wu et al., 2011). In this study, we used Cor.At cells, produced through in vitro differentiation of mouse iPSC coupled with puromycin selection of cardiomyocytes (Kolossov et al., 2005). Unlike H9c2 cardiomyoblasts, Cor.At cells have limited proliferative capacity similar to primary cells, as determined through BrdU incorporation assays (Kolossov et al., 2006), and can be transplanted into mouse hearts. These cells express all relevant cardiac ion channels $\left(\mathrm{K}^{+}, \mathrm{Ca}^{2+}, \mathrm{Na}^{+}\right)$(Abassi et al., 2012) and the gap junction channel protein connexin-43 (Frank et al., 2014), the predominant connexin expressed by cardiomyocytes (Severs et al., 2004). This is an indication of the ability for electric coupling of these cells, as shown in immunostaining, and enables the cells to beat synchronously in culture. Patch clamp analysis, as well as multi-electrode array (MEA) recordings, demonstrated the normal electrophysiological properties of these cells, and DOX treatment in Cor.At cardiomyocytes significantly decreased overall beating rate and induced an irregular beating pattern similar to other compounds that induce arrhythmia (Abassi et al., 2012). Overall, the data obtained so far suggest that these cells present some advantages to study DOX cardiotoxicity. Still, no information is available on how mitochondrial stress responses and metabolism respond to DOX treatment in the Cor.At cardiomyocyte cell system. This limitation hinders a more complete picture of the mechanisms underlying DOX toxicity in beating mouse stem cell-derived cardiomyocytes. Our objective is thus to investigate mitochondrial stress responses triggered by DOX on Cor.AT cells, focusing on oxidative phosphorylation, regulation of pyruvate oxidation, and p53 signaling.

\section{Material and methods}

\subsection{Cell culture}

Vials of mouse iPSC-derived cardiomyocytes (Cor.At, cat \#Ax-CMC02) were obtained from Axiogenesis, NCardia (Cologne, Germany). Frozen Cor.At cardiomyocytes were rapidly thawed by gentle agitation in a $37^{\circ} \mathrm{C}$ water bath and immediately transferred into $50 \mathrm{ml}$ centrifuge tubes filled with $8 \mathrm{ml}$ Cor.At Culture Medium (cat \#Ax-M-MC250). The cryotube was rinsed with an additional $1 \mathrm{ml}$ of medium to collect remaining cells and pipetted into the same centrifuge tube. The cells were then centrifuged at $200 \times g$ for $5 \mathrm{~min}$ and the pellet was carefully resuspended in culture medium containing puromycin. Cells were counted and seeded on fibronectin-coated culture plates at a density of $1 \times 10^{5}$ cells.cm ${ }^{-2}$ and incubated at $37^{\circ} \mathrm{C}$ in $5 \% \mathrm{CO}_{2} / 95 \%$ air for 1 week before experiments were performed, with the culture medium being replaced every two days. Cells were then incubated with DOX $(0$, 0.5 or $1 \mu \mathrm{M}$ ) for $24 \mathrm{~h}$. Choice of DOX concentrations and duration of exposure was based in previous studies (Sardao et al., 2009a; Branco et al., 2012; Moreira et al., 2014; Deus et al., 2015). For the pre-incubation experiments, the following compounds were added to cells prior to DOX treatment: $50 \mu \mathrm{M}$ z-VAD-fmk for $1 \mathrm{~h}, 100 \mu \mathrm{M} N$-acetyl cisteine (NAC) for $2 \mathrm{~h}, 30 \mu \mathrm{M}$ pifithrin-alpha (Pfa) for $30 \mathrm{~min}, 3 \mathrm{mM}$ dichloroacetate (DCA) for $24 \mathrm{~h}$.

\subsection{Microscopy}

To evaluate DOX-induced changes on cell morphology and contractile function, cells were visualized in a Nikon Eclipse Ti-S microscope (Nikon Instruments Inc., NY, USA). For analysis of mitochondrial transmembrane electric potential $(\Delta \psi \mathrm{m})$ and nuclear morphology cells were rinsed with PBS $1 \times$ and incubated for $30 \mathrm{~min}$ in microscopy medium $\left(120 \mathrm{mM} \mathrm{NaCl}, 3.5 \mathrm{mM} \mathrm{KCl}, 0.4 \mathrm{mM} \mathrm{KH}_{2} \mathrm{PO}_{4}, 20 \mathrm{mM}\right.$ HEPES, $5 \mathrm{mM} \mathrm{NaHCO}_{3}, 1.2 \mathrm{mM} \mathrm{NaSO}_{4}, 1.3 \mathrm{mM} \mathrm{MgCl}_{2}, 1.3 \mathrm{mM} \mathrm{CaCl}_{2}, 15 \mathrm{mM}$ glucose at pH 7.4) with $\mathrm{TMRM}^{+}(100 \mathrm{nM})$ and Hoechst $33342(1 \mu \mathrm{g} /$ $\mathrm{ml}$ ), after DOX treatment. After incubation, cells were imaged in a Nikon Eclipse Ti-S microscope (Nikon Instruments Inc., NY, USA).

\subsection{RNA and protein isolation}

PureZOL Reagent (Bio-Rad, Hercules, CA, USA) was used to isolate RNA and protein fractions from the same sample. For this purpose, Cor.At cells were cultured in 6 multiwell plates. After aspiration of the culture medium, $1 \mathrm{ml}$ of PureZOL was added to each well, the reagent was mixed by pipetting up and down, and incubated at room temperature (RT) for $5 \mathrm{~min}$, to allow the disruption of nucleoprotein complexes. The content was transferred to a $1.5 \mathrm{ml}$ microtube and $0.2 \mathrm{ml}$ of chloroform was added, followed by vigorous mixing for $15 \mathrm{~s}$. The samples were incubated for $5 \mathrm{~min}$ and centrifuged at $12000 \times g$ for $15 \mathrm{~min}$ at $4{ }^{\circ} \mathrm{C}$, to separate the sample into 3 phases: aqueous phase (RNA), interphase (DNA) and organic phase (protein).

\subsubsection{RNA extraction}

The aqueous phase was immediately transferred to a new microtube and $0.5 \mathrm{ml}$ of isopropyl alcohol was added and incubated for $5 \mathrm{~min}$ at RT, for RNA precipitation. Another centrifugation was performed at $12000 \times g$ for $10 \mathrm{~min}$ at $4{ }^{\circ} \mathrm{C}$ and the supernatant was discarded. To wash the RNA white pellet, $1 \mathrm{ml}$ of $75 \%$ ethanol was used, followed by vortexing and centrifugation at $7500 \times g$ for $5 \mathrm{~min}$ at $4^{\circ} \mathrm{C}$. Supernatant was again discarded, and the pellet dried for $5 \mathrm{~min}$. Lastly the pellet was resuspended in $20 \mu \mathrm{l}$ of RNase-free water and stored at $-80^{\circ} \mathrm{C}$.

\subsubsection{Protein extraction}

After the removal of the aqueous phase, $0.3 \mathrm{ml}$ of $100 \%$ ethanol was added to the microtube containing the two other phases. After $3 \mathrm{~min}$ at RT, the samples were centrifuged at $2000 \times g$ for $5 \mathrm{~min}$ at $4{ }^{\circ} \mathrm{C}$ and the supernatant transferred for a new Eppendorf tube. To precipitate the proteins, $1.5 \mathrm{ml}$ of isopropyl alcohol was added and incubated for $10 \mathrm{~min}$ at RT, followed by centrifugation at $12000 \times \mathrm{g}$ for $10 \mathrm{~min}$ at $4^{\circ} \mathrm{C}$. After discarding the supernatant, the pellet was washed with $2 \mathrm{ml}$ of $0.3 \mathrm{M}$ guanidine hydrochloride in $10 \%$ ethanol, incubated $20 \mathrm{~min}$ at $\mathrm{RT}$, centrifuged at $7500 \times \mathrm{g}$ for $5 \mathrm{~min}$ at $4^{\circ} \mathrm{C}$, and the supernatant was discarded. These steps were performed 3 times. Then, $2 \mathrm{ml}$ of ethanol was added, and the sample was vortexed and centrifuged at $7500 \times g$ 
for $5 \mathrm{~min}$ at $4{ }^{\circ} \mathrm{C}$. After discarding the supernatant, the pellet was dried for $10 \mathrm{~min}$ and resuspended in $50 \mu \mathrm{l}$ of $1 \%$ SDS at $50^{\circ} \mathrm{C}$. For the analysis of PDH levels, and PDH phosphorylation by western blotting, the protein samples were prepared as described for the PDH activity assay. The protein was quantified by the BCA method (Pierce, Rockford, IL, USA) using bovine serum albumin (BSA) as a standard.

\subsection{Western blotting}

Samples were heated at $55^{\circ} \mathrm{C}$ (for OXPHOS) or $95^{\circ} \mathrm{C}$ for $5 \mathrm{~min}$ in a $2 \times$ Laemmli sample loading buffer (Bio-Rad, Hercules, CA, USA), and equivalent amounts of protein were separated in $10 \%$ polyacrylamide gel electrophoresis and electrophoretically transferred to a PVDF membrane. After membrane blocking with 5\% nonfat dry milk (BioRad) in Tris-Buffered Saline Tween (TBS-T; $50 \mathrm{mM}$ Tris-HCl, $\mathrm{pH} 8$; $154 \mathrm{mM} \mathrm{NaCl}$ and $0.1 \%$ Tween 20) for $2 \mathrm{~h}$ at RT under continuous stirring, membranes were incubated overnight at $4{ }^{\circ} \mathrm{C}$, under stirring, with the antibodies directed against PARP-1 (Santa Cruz, Dallas, TX, USA, sc-7150, rabbit), OXPHOS subunits (Abcam, Cambridge, UK, ab110413, mouse), HK2 (Cell Signaling, Danvers, MA, USA, \#2867, rabbit) p53 (Cell Signaling, \#2524, mouse), SOD2 (Abcam, ab16956, mouse), PDH (Cell Signaling, \#3205, rabbit) or phospho-PDH Ser293 (Millipore, \#ABS204, rabbit). Once incubation was complete, membranes were incubated with horseradish peroxidase (HRP)- conjugated secondary antibodies for $1 \mathrm{~h}$ at RT under continuous agitation. Membranes were washed again and incubated with ECL (Bio-Rad), for 5 min maximum at RT. Band intensity was analyzed in a UVP Biospectrum 500 Imaging System (UVP, LLC, Cambridge, UK). Before blocking, the membranes were stained with Ponceau $S$ reagent to confirm equal protein loading in each membrane. Ponceau $S$ labels a wide range of proteins independently of drug treatment, being a reliable method for protein normalization in western blotting (RomeroCalvo et al., 2010). Band density was measured using the Image $1.45 \mathrm{~S}$ software (NIH, Bethesda, USA).

\subsection{Analysis of gene expression by quantitative real-time PCR}

Total RNA was extracted with PureZOL Reagent, as described above, and its concentration and purity were evaluated using a Nanodrop 2000 (ThermoScientific, Waltham, MA, USA). RNA integrity was verified using the Experion RNA StdSens kit (Bio-Rad), and RNA was converted into cDNA using the iScript cDNA synthesis kit (BioRad), following the manufacturer's instructions. RT-PCR was performed using the SsoFast EvaGreen Supermix, in a CFX96 real time-PCR system
(Bio-Rad), with the primers defined in Table 1, at $500 \mathrm{nM}$. Amplification of $25 \mathrm{ng}$ cDNA was performed with an initial cycle of $30 \mathrm{~s}$ at $95^{\circ} \mathrm{C}$, followed by 40 cycles of $5 \mathrm{~s}$ at $95^{\circ} \mathrm{C}$ plus $5 \mathrm{~s}$ at the annealing temperature (Ta) referred in Table 1. At the end of each cycle, EvaGreen fluorescence was recorded to enable determination of Cq. After amplification, melting temperature of the PCR products were determined by performing melting curves, and amplicon length was confirmed by agarose gel electrophoresis. For each set of primers, amplification efficiency was assessed. Relative normalized expression was determined by the CFX96 Manager software (v. 3.0; Bio-Rad), using 18S RNA as reference.

\subsection{Cell mass}

The sulforhodamine B (SRB) assay (Vichai and Kirtikara, 2006) was used to measure cell mass through determination of the total cell protein. At the end of DOX treatment, the culture medium was removed, and cells were washed with PBS $1 \times$ and fixed in $1 \%$ acetic acid in icecold methanol overnight at $-20^{\circ} \mathrm{C}$. Cells were then incubated with $0.05 \%(w / v)$ SRB for $1 \mathrm{~h}$ at $37^{\circ} \mathrm{C}$. Subsequently, SRB was removed and wells were washed with $1 \%$ acetic acid to remove unbound stain. Dye bound to cellular proteins was extracted with $10 \mathrm{mM}$ Tris-base solution, $\mathrm{pH} 10$, and its absorbance was read at $540 \mathrm{~nm}$ in a Victor X3 multiplate reader (Perkin-Elmer, Waltham, MA, USA).

\subsection{ATP levels}

Cell viability based on ATP measurement was assessed using CellTiter Luminescent Cell Viability Assay (Promega, Madison, WI, USA). Briefly, cells were seeded in a 96-well plate and, at the day of the assay, the medium was removed from the wells and replaced by $50 \mu \mathrm{l}$ of fresh medium. $50 \mu \mathrm{l}$ of the Cell Titer-Glo ${ }^{\circledR}$ reagent was added and mixed for $2 \mathrm{~min}$ on an orbital shaker to promote cell lysis. The plate was incubated for $10 \mathrm{~min}$ and the luminescent signal was recorded using Cytation $^{\mathrm{TM}} 3$ microplate reader (BioTek, USA).

\subsection{Caspase activity}

Caspase-9 and -3/7-like activities were evaluated using the Promega Caspase-GLO assays (Promega, Madison, WI, USA), Caspase-Glo 9 and Caspase-Glo 3/7, respectively. Cells were seeded in white 96 multiwell plates and the assay was performed at the end of DOX treatment, following the instructions provided by the manufacturer.

Table 1

Sequences of primers used for the analysis of gene expression.

\begin{tabular}{|c|c|c|c|c|}
\hline Gene & Accession number & Fwd primer & Rev primer & $\mathrm{Ta}\left({ }^{\circ} \mathrm{C}\right)$ \\
\hline Ant1 & NM_007450 & TGACACTGCCAAGGGGATGC & GCCAGACTGCATCATCATCCT & 63 \\
\hline Atm & NM_007499 & GAGGCCTAGGATTTCACGAAG & TGTTCGATCCTCATCAAGGTG & 60 \\
\hline Atr & NM_019864 & CCTCAAACCGCTTTTTCGCA & ATCCGGCCTTTTGTTGAGACT & 63 \\
\hline Bax & NM_007527 & TGCTACAGGGTTTCATCCAGG & TCCACGTCAGCAATCATCCT & 63 \\
\hline$B c l 2$ & NM_009741 & ATAACGGAGGCTGGGATGC & GGCAGGTTTGTCGACCTCA & 63 \\
\hline Bpgm & NM_007563 & TACAAAGTGTGCGATGTG & CGTCTGAGATACCTTCCA & 60 \\
\hline$C d k 1$ & NM_007659 & ACACACACGAGGTAGTGACG & GTCAATCTCTGAGTCGCCGT & 63 \\
\hline$C d k 2$ & NM_183417 & CGGAGTGGTGTACAAAGCCA & TTCAGTCTCAGTGTCGAGCC & 60 \\
\hline Chk1 & NM_007691 & AAAGGACTGCTTGTCGCTGT & TCCATAGGCACCTTCTCCCA & 60 \\
\hline Chk2 & NM_016681 & TTCTTTTCATCTGCCTAAGTGGG & CCTCCTCTGTGGTAAGCCGA & 62 \\
\hline Hif1a & NM_001313919 & ССTTAACCTGTCTGCCACTT & TAATGTTCCAATTCCTGCTGCTT & 60 \\
\hline$H k 2$ & NM_013820 & CCTGGTTTCAAAGCGGTCGG & TACTGGTCAACCTTCTGCACTTG & 63 \\
\hline$M d m 2$ & NM_010786 & TGGCGTAAGTGAGCATTC & CCGATAGACCTCATCATCCT & 60 \\
\hline Noxa & NM_021451 & GGTGCCAGCAGACTTGAAGG & GCATTTCCATCAACCGGCG & 63 \\
\hline$P d k 4$ & NM_013743 & GTGGACCCCGTTACCAATCA & GCACACTCAAAGGCATCTTGG & 60 \\
\hline Puma & NM_133234 & GAGCGGCGGAGACAAGAA & AGGAGTCCCATGAAGAGATTGT & 60 \\
\hline p53 & NM_011640 & TTCATTGGGACCATCCTGGC & GGCAGTCATCCAGTCTTCGG & 63 \\
\hline Vdac1 & NM_011694 & GTAACACTCGCTTCGGAAT & CGTCAGTTTGATACCTGGTTT & 60 \\
\hline Rna18S & NR_003278 & GGACAGGATTGACAGATTGAT & CCAGAGTCTCGTTCGTTATC & 60 \\
\hline
\end{tabular}




\section{9. $P D H$ activity}

PDH activity was measured using a commercial assay kit (\#MAK183, Sigma) according to manufacturer's instructions. Briefly, $9 \times 10^{5}$ Cor.At cells were lysed in $100 \mu \mathrm{lDH}$ assay buffer and $10 \mu \mathrm{l}$ of the cell lysate was used per reaction. After the addition of the reaction mixture, consisting of assay buffer, PDH substrate and developer, the absorbance was measured continuously at $450 \mathrm{~nm}$ every $1 \mathrm{~min}$ for $80 \mathrm{~min}$ total, while the plate was incubated at $37^{\circ} \mathrm{C}$. Only measurements within the linear range of the assay were used for PDH activity calculation and sample blanks were used for each sample correction.

\subsection{Seahorse stress tests}

Oxygen consumption rate (OCR) and extracellular acidification rate (ECAR) were determined using a Seahorse XFe96 analyzer (Agilent Technologies, Santa Clara, CA) and the Seahorse XF Cell Mito Stress Test. Cor.At were seeded into Seahorse XFe96 well plates at a density of $1.0 \times 10^{4}$ cells/well/ $80 \mu l$. One hour prior the assay the plate was rinsed twice with PBS, $175 \mu$ of Cor.At culture medium was added and cells were incubated for $1 \mathrm{~h}$ at $37^{\circ} \mathrm{C}$ without $\mathrm{CO}_{2}$. Cor.At medium was used in the assay, including in the preparation of the loaded compounds. A constant volume of $25 \mu \mathrm{l}$ of each compound was pre-loaded into the respective ports of the cartridge (Port A: oligomycin, final concentration: $1 \mu \mathrm{M}$; Port B: FCCP, final concentration: $4 \mu \mathrm{M}$; Port C: a mix of rotenone/antimycin A, final concentration: $2 \mu \mathrm{M}$ ). Measurements were performed in five to six replicates. OCR and ECAR values were normalized to the cell mass, determined by the SRB assay, and analyzed using Wave v2.3 software (Agilent Technologies, Santa Clara, CA).

\subsection{Statistical analysis}

Data were expressed as mean \pm SEM for the number of experiments indicated in the figure legends. Comparisons were performed using Mann-Whitney $U$ test when comparing 2 conditions, KruskalWallis H-test followed by Dunn's post hoc analysis was used for multiple conditions comparison. For parametric analysis, multiple comparisons were performed using one-way ANOVA followed by Bonferroni posthoc test. Significance was accepted with $\mathrm{p}$ value $<0.05$.

\section{Results}

\subsection{DOX induced dose-dependent morphological and functional changes} associated with mitochondrial depolarization and apoptotic hallmarks

To evaluate DOX cardiotoxicity, cardiomyocytes were incubated with $0,0.5$ or $1 \mu \mathrm{M}$ DOX, and cell morphology and mass were evaluated after $24 \mathrm{~h}$ of treatment (Fig. 1). Alterations of cell morphology were apparent for both DOX concentrations, with the highest concentration inducing more evident changes (Fig. 1A), accompanied by desynchronization of cardiomyocyte beating, possibly due to lower intercellular surface contacts due to DOX toxicity (Supplementary Videos 1-3). Average nuclear area was significantly decreased for $1 \mu \mathrm{M}$ DOX, being $50 \%$ lower in average when compared to control, and $37 \%$ lower when compared to $0.5 \mu \mathrm{M}$ DOX (Fig. 1B). This mostly resulted from a decrease in the number of cells with larger nuclei and a correspondent increase in cells with smaller ones (Fig. 1C). However, cell protein mass was not significantly affected by DOX at the concentrations used (Fig. 1D). The ATP levels, on the other hand, were significantly reduced after DOX treatment (Fig. 1E).

Morphological changes accompanied alterations in mitochondrial polarization, assessed by $\mathrm{TMRM}^{+}$labeling intensity, and by increased nuclear apoptotic morphology, analyzed after labelling with Hoechst
A

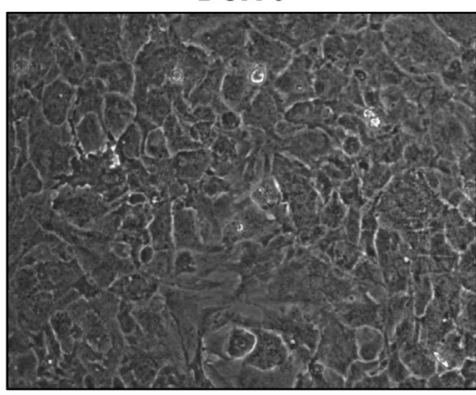

DoX 0.5

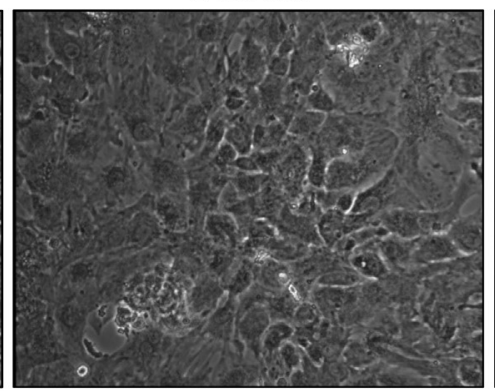

DoX 1

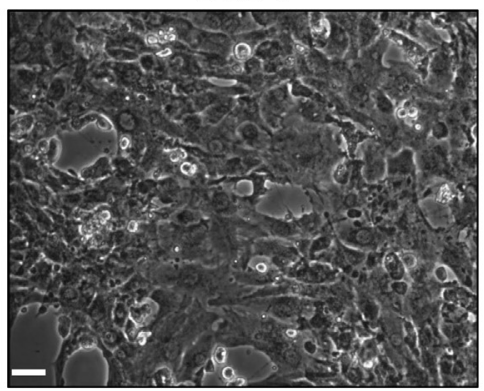

B

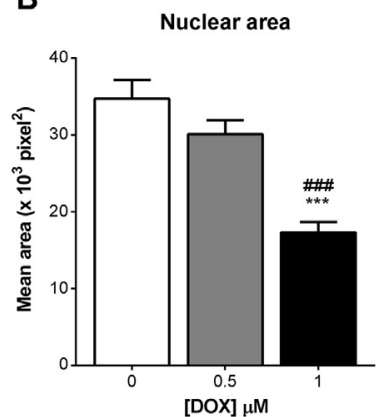

C

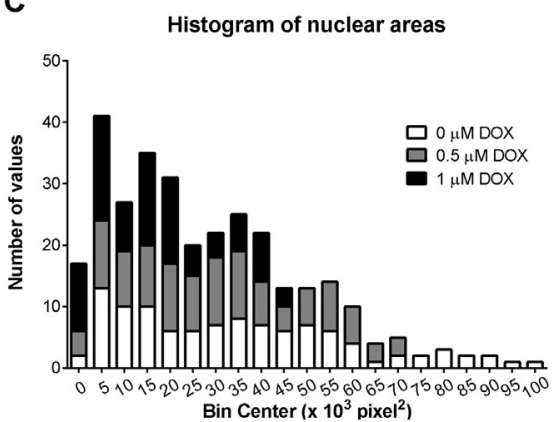

D

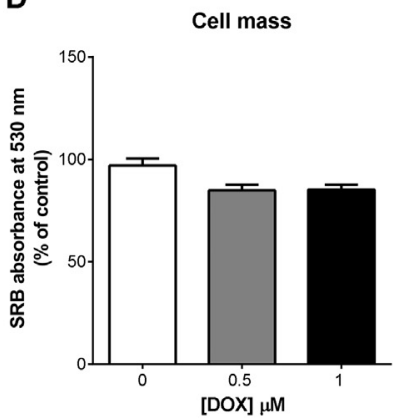

E

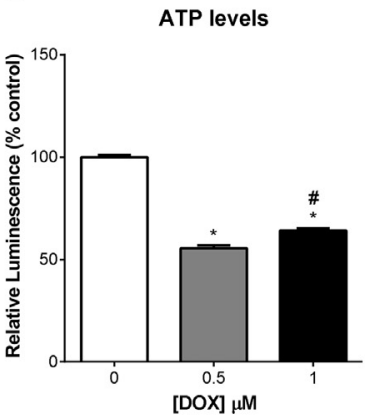

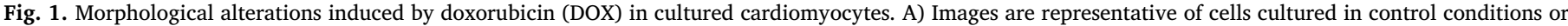

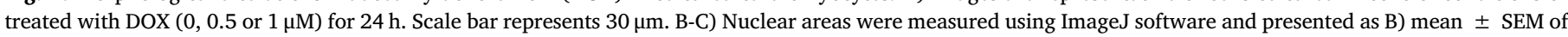

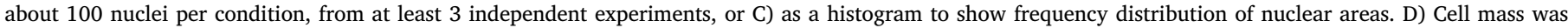

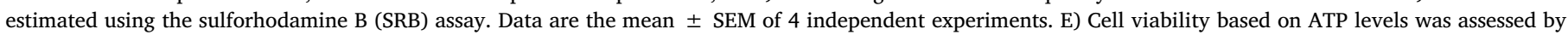

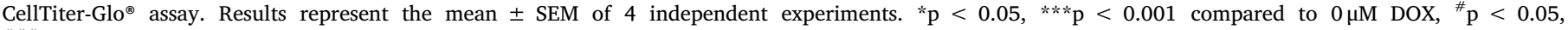

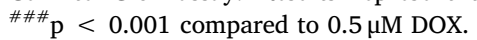


A
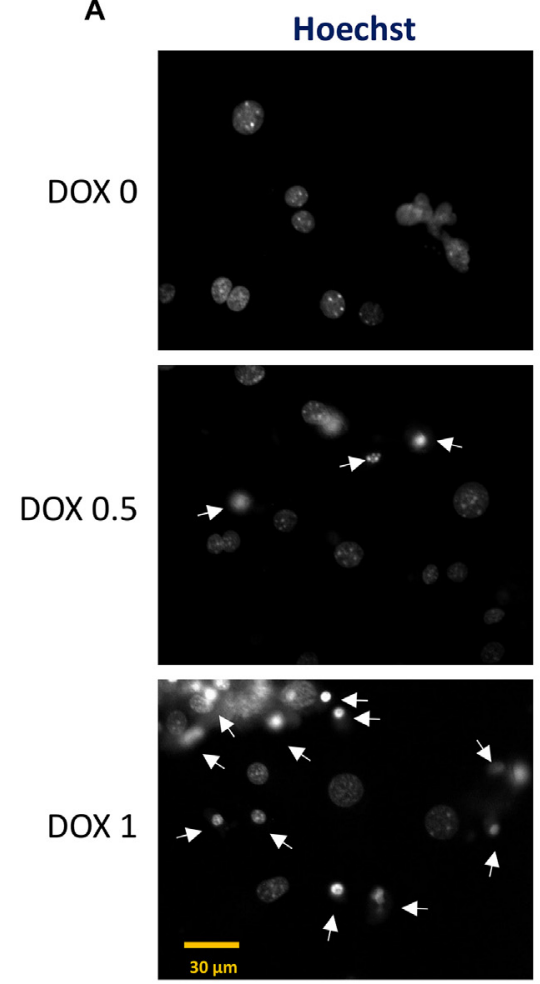

B

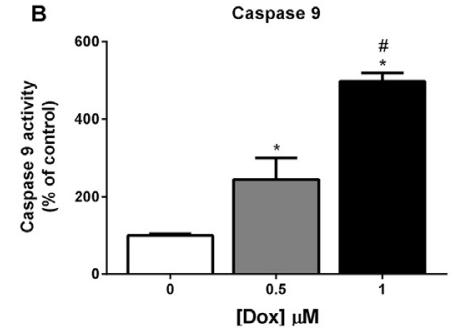

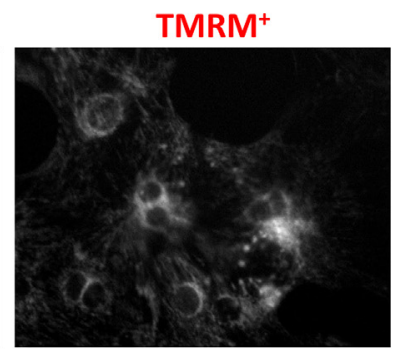
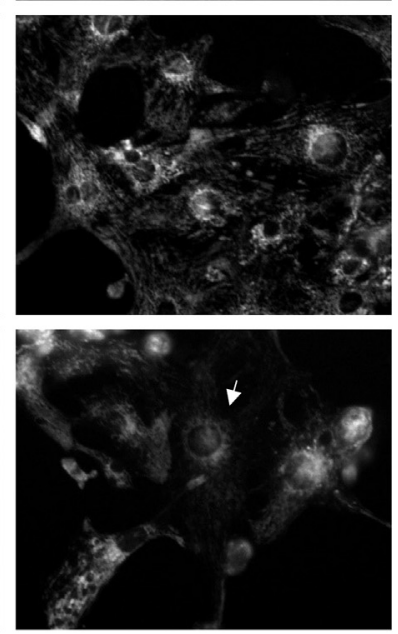

c

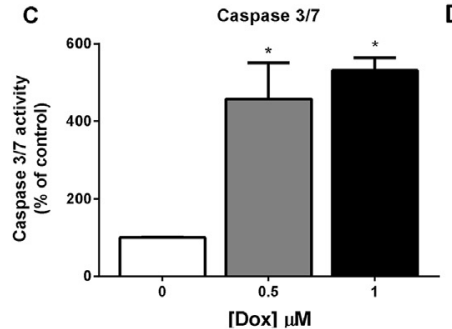

Overlay
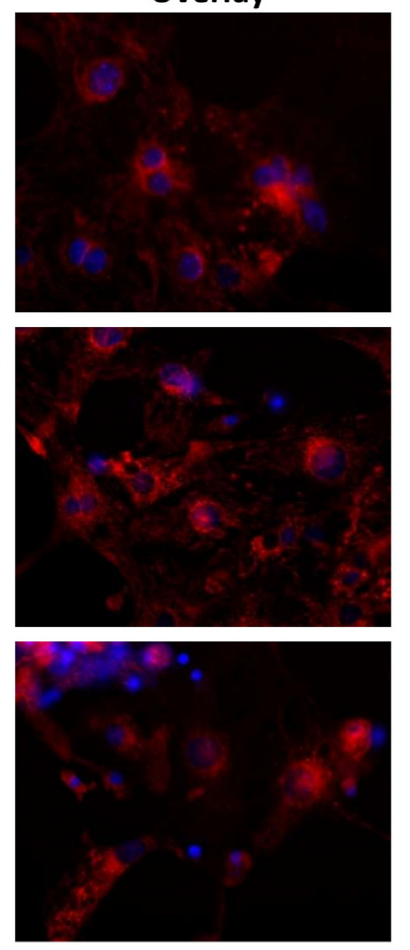

D

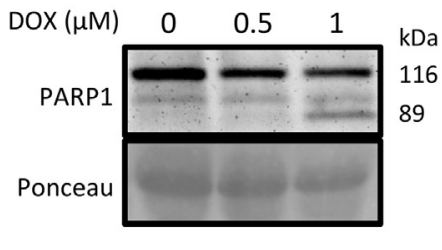

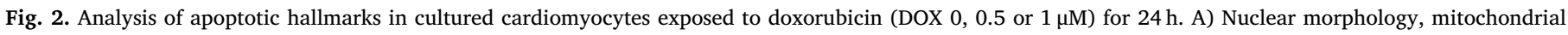

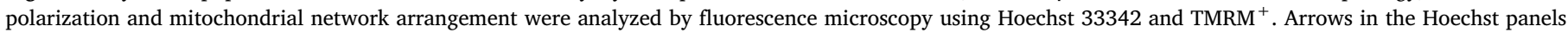

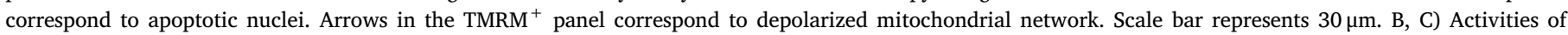

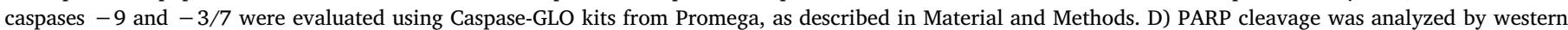
blotting. Data are representative from 3 to 4 independent experiments. ${ }^{*} \mathrm{p}<0.05$ compared to $0 \mu \mathrm{M} \mathrm{DOX}$, ${ }^{\#} \mathrm{p}<0.05$, compared to $0.5 \mu \mathrm{M}$ DOX.

33342 (Fig. 2A). At the lower concentration, DOX treatment resulted in a small increase in the number of apoptotic nuclei and appeared to increase perinuclear mitochondrial polarization, which can be an early feature of apoptosis that precedes caspase activation (Sanchez-Alcazar et al., 2000; Giovannini et al., 2002; Iijima et al., 2003; Liu et al., 2005; Cao et al., 2007). In accordance, the activities of caspases -9 and -3 / 7 were also significantly increased under these conditions (Fig. 2B, C). In comparison with control conditions, caspase- 9 activity was increased by $\sim 2.4$ fold in cells treated with $0.5 \mu \mathrm{M}$ DOX, (Fig. 2B), whereas caspase-3/7 activity increased by $\sim 4.6$ fold (Fig. $2 \mathrm{C}$ ). In cells treated with $1 \mu \mathrm{M}$ DOX, an increase in the number of apoptotic nuclei and a decrease in mitochondrial polarization was observed, together with increased activities of caspases -9 ( $\sim 5$ fold) and $-3 / 7$ ( $\sim 5.3$ fold), and increased protein content of the PARP-1 fragment (Fig. 2D) resulting from caspase-3-mediated PARP-1 cleavage.

3.2. DOX induced p53-associated caspase activation and decreased SOD2 protein content

DOX cardiotoxicity has been described to be mediated by p53 and oxidative stress (Sardao et al., 2009a; Carvalho et al., 2014). In our cell model, both drug concentrations increased p53 (Fig. 3A) and decreased
SOD2 (Fig. 3B) protein contents. The levels of p53 were increased by $\sim 4.6$ fold in cells treated with $0.5 \mu \mathrm{M}$ DOX and $\sim 3.6$ fold in cells treated with $1 \mu \mathrm{M}$ DOX. SOD2 protein levels were decreased by $\sim 30 \%$ for the lower DOX concentration and $\sim 37 \%$ for $1 \mu \mathrm{M}$ DOX. Activation of caspases by DOX was completely prevented by pre-incubation with the non-selective caspase inhibitor z-VAD-fmk (Fig. 3C, D). Pre-incubation with Pfa, a p53 inactivator that blocks p53-dependent transcriptional activation and apoptosis (Komarov et al., 1999), partially prevented caspase- 9 activation by DOX at $1 \mu \mathrm{M}$ (Fig. 3C), and completely prevented caspase $3 / 7$ activation by DOX at 0.5 and $1 \mu \mathrm{M}$ (Fig. 3D). The antioxidant NAC did not present significant protective effects against DOX-induced caspase activation in this cell model (Fig. 3C, D). At the concentrations used in this study, Pfa, NAC and zVAD-fmk did not induce a significant decrease in cardiomyocyte cell mass, in the presence or in the absence of DOX (Supplementary Fig. 1).

3.3. DOX dose-dependently affected p53 target transcripts associated with mitochondria-dependent apoptosis and DNA-damage response

Since DOX-induced cardiomyocyte apoptosis seems to be dependent on p53, we next evaluated the mRNA levels of p53-target genes as well as other genes associated with the regulation of the p53 pathway 
(Fig. 4). DOX effects on gene transcription were dependent on the drug concentration. The lower DOX concentration induced an increase in transcripts for the p53 target genes Puma ( 4.6 fold) (Fig. 4C), Noxa ( $\sim 17.5$ fold) (Fig. 4D) and Bax ( $\sim 2.1$ fold) (Fig. 4E), which are proapoptotic, and also Mdm2 ( $\sim 2.6$ fold) (Fig. 4B), a gene directly related with the regulation of the p53 pathway (Stindt et al., 2011). The levels of p53 also showed a non-statistically increase $(\sim 1.7$ fold $)$ for the lower DOX concentration (Fig. 4A). For the higher DOX concentration, the levels of all transcripts were similar to the control situation, except for Noxa, which also showed a non-statistically significant tendency to increase ( $\sim 3.5$ fold) (Fig. 4D) and Bax, which was significantly decreased ( $-70 \%$ ) (Fig. 4E). The mRNA levels of the anti-apoptotic gene Bcl-2 were decreased in cells exposed to both DOX concentrations ( $-58 \%$ for $0.5 \mu \mathrm{M}$ DOX and $-88 \%$ for $1 \mu \mathrm{M}$ DOX) (Fig. $4 \mathrm{~F}$ ). Since $\mathrm{p} 53$ activation is associated with DNA damage, we also evaluated transcripts associated with p53-related DNA damage response (Fig. 4G-I). From the genes studied, Atm and Cdk2 transcription was not affected by any of the DOX concentrations tested (Supplementary Fig. 2). The expression of Atr (-63\%) (Fig. 4G), Chk2 (-42\%)(Fig. 4H) and Cdk1 $(-80 \%$ ) (Fig. $4 \mathrm{I}$ ) was significantly decreased in cells treated with $1 \mu \mathrm{M}$ DOX, in comparison with control cells. The expression of Chk1 (Supplementary Fig. 2B) decreased $(-50 \%)$ for both DOX concentrations, although the difference was only statistically significant for cells treated

A
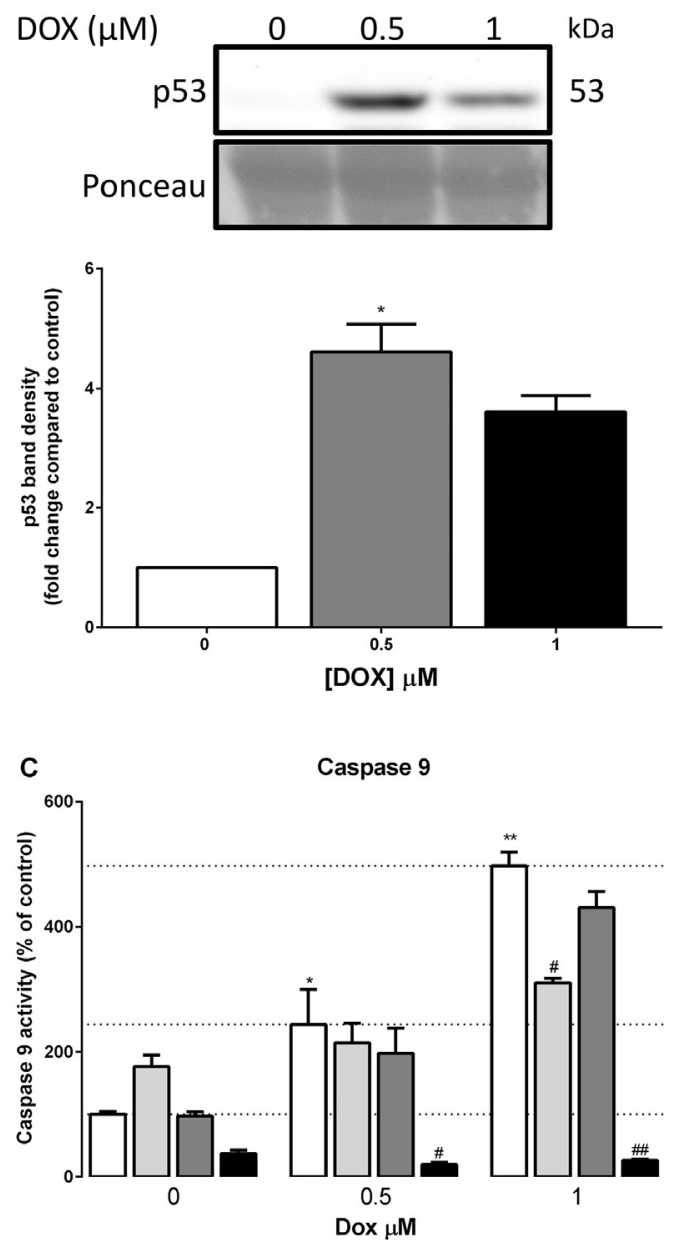

with $0.5 \mu \mathrm{M}$ DOX.

\subsection{DOX altered proteins and transcripts associated with mitochondrial bioenergetics}

Since the results suggested that DOX treatment resulted in mitochondrial dysfunction in our cell model, we next evaluated the protein content of several OXPHOS subunits, as well as the glycolytic enzyme hexokinase-2 (HK2) (Fig. 5). Decreases in protein content of OXPHOS subunits NDUFB8 (complex I) (Fig. 5A) and ATP5A (ATP synthase) (Fig. 5E) were only observed in cells treated with $1 \mu \mathrm{M} \mathrm{DOX}$, by $\sim 44 \%$ and $\sim 26 \%$, respectively. However, HK2 protein content (Fig. 5F) was decreased by $\sim 60 \%$ in cells treated with both DOX concentrations. Since DOX may interfere with DNA and affect gene transcription, we measured the abundance of mRNAs encoding genes involved in mitochondrial bioenergetics. We observed a dose-dependent decrease in Hk2 and Hif1 $\alpha$ transcripts (Fig. 6A, B). Interestingly, the two DOX concentrations used had a different impact on Pdk4 and Bpgm transcripts, which were only increased after treatment with $0.5 \mu \mathrm{M}$ DOX (Fig. 6E, F), by $\sim 5.3$ and $\sim 2.3$ fold, respectively. Ant1 and Vdac1 transcripts were not significantly affected by any of the DOX concentrations used (Fig. 6C, D). These results suggest a selective and dosedependent impact of DOX over gene transcription. A clustergram

B
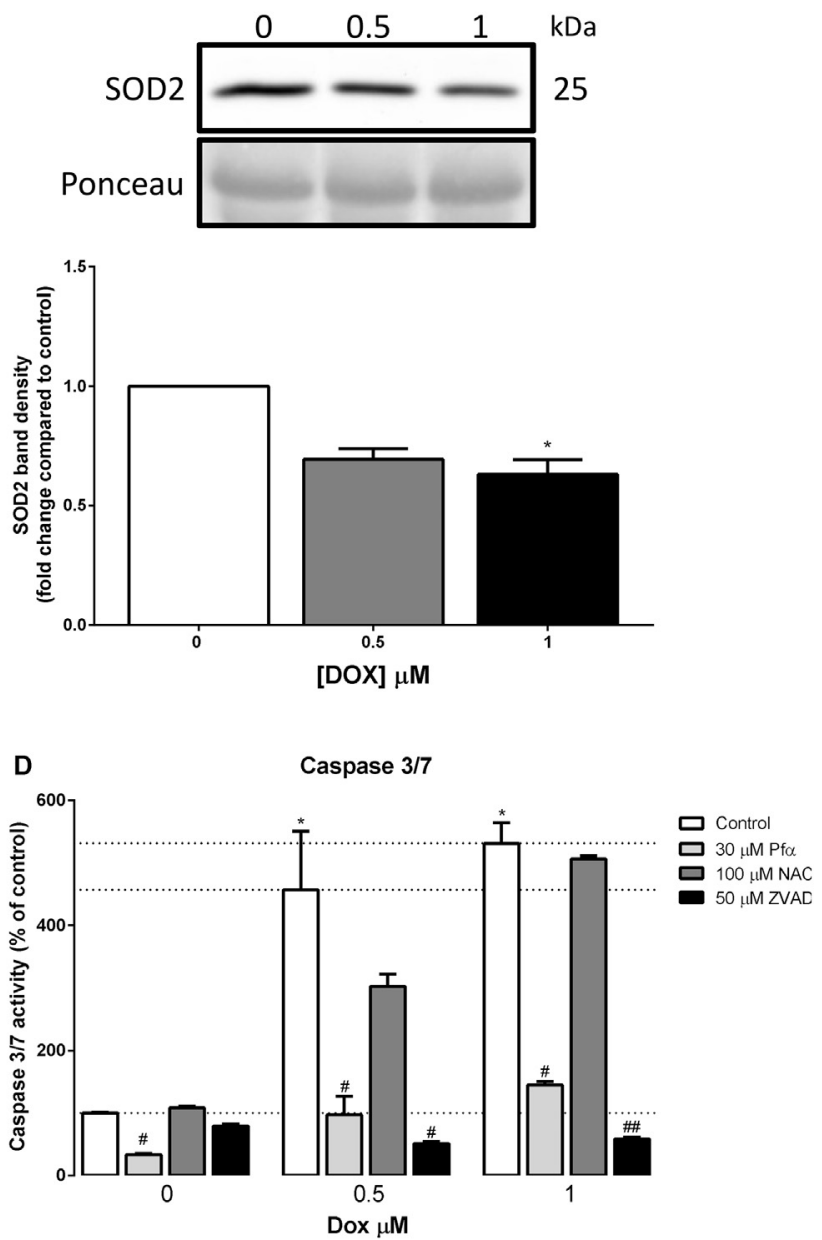

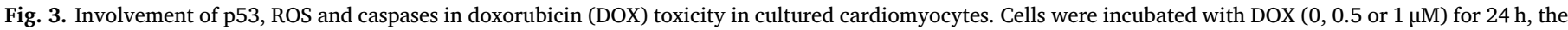

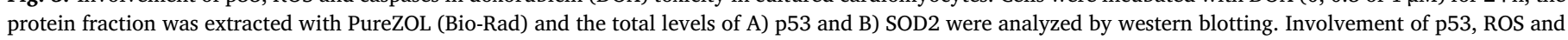

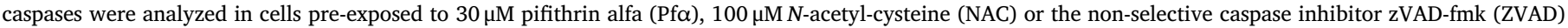

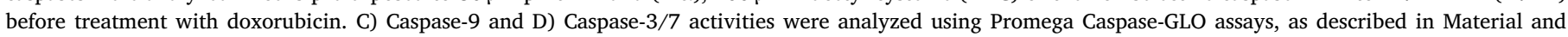

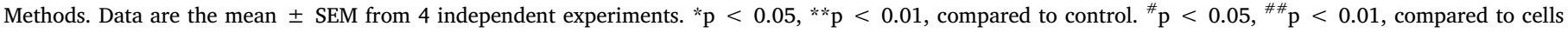
treated only with DOX. 


\section{p53 pathway and apoptosis}

A

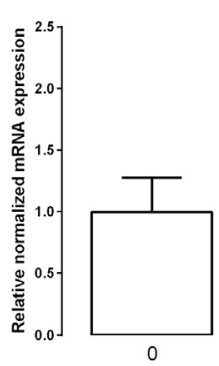

D

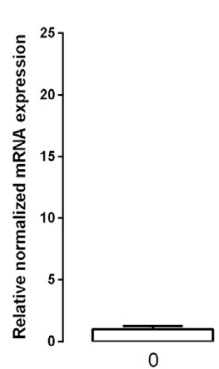

p53

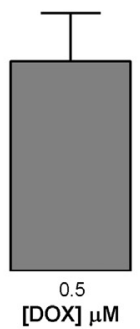

Noxa

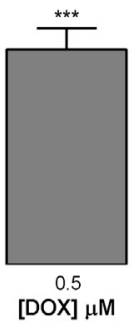

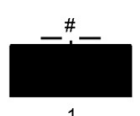

1<smiles>[Tl]</smiles>

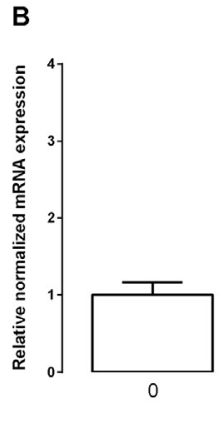

E

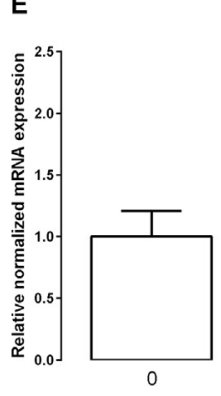

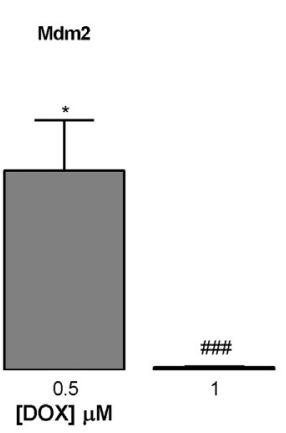

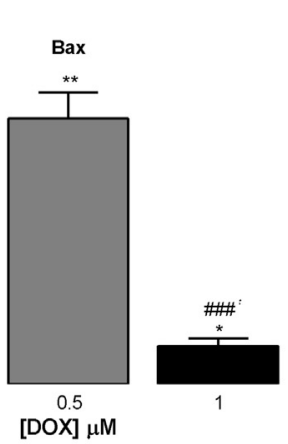

C

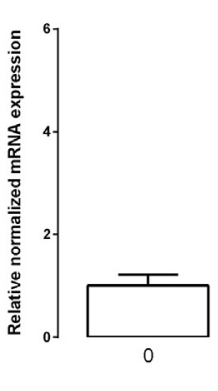

F

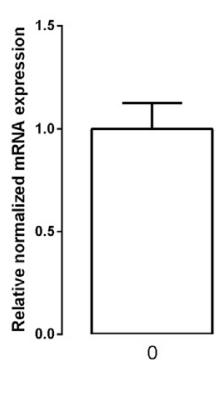

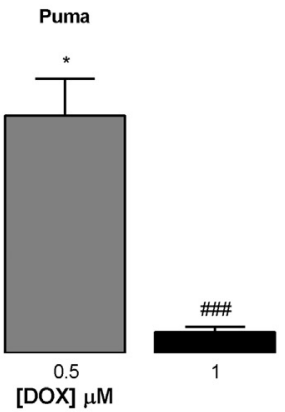

Bc12

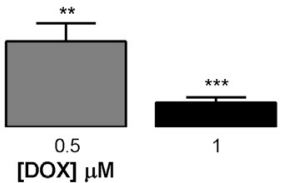

\section{DNA damage response}

G

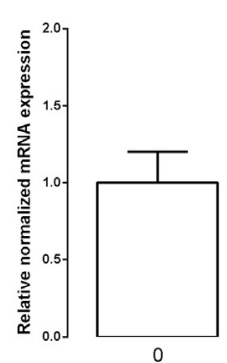

Atr

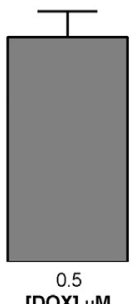

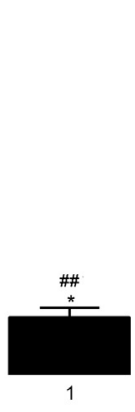

H

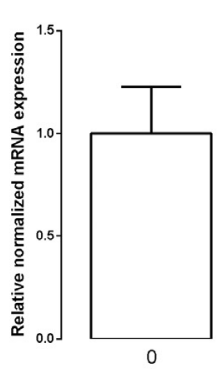

Chk2

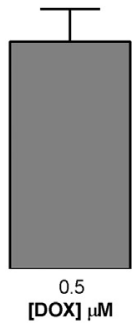

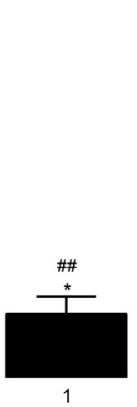

I

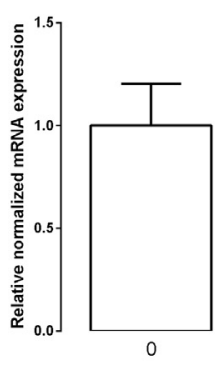

Cdk1

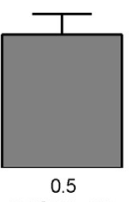

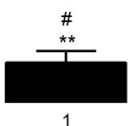

[DOX] $\mu \mathrm{M}$

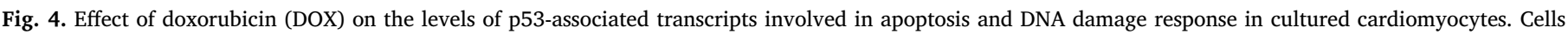

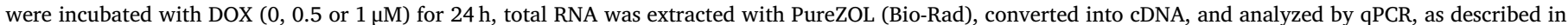

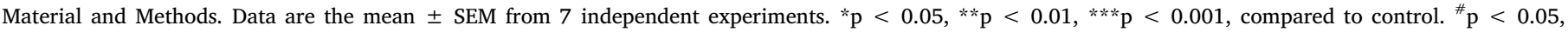
${ }^{\# \#} \mathrm{p}<0.01,{ }^{\# \# \#} \mathrm{p}<0.001$ compared to cells treated with $0.5 \mu \mathrm{M}$ DOX.

showing the changes in expression of all the transcripts studied is presented as Supplementary Fig. 3.

The increase in Pdk4 transcription suggests that DOX may have led to metabolic alterations through a decrease in PDH activity, which would result in decreased flux of pyruvate to the TCA cycle and the OXPHOS (Fig. 7A) (Zhang et al., 2015). Thus, we evaluated the levels of phospho-PDH and PDH activity (Fig. 7B-D). In agreement with the increase in Pdk4 transcript levels, treatment with $0.5 \mu \mathrm{M}$ DOX induced an increase in phospho-PDH levels (Fig. 7B-C), which seems to result in decreased PDH activity, although the results did not reach statistical significance due to a limitation in the number of cells available for this particular experiment (Fig. 7D).

Next, we measured ATP levels, and evaluated bioenergetic parameters by simultaneously following Oxygen Consumption Rate (OCR) and Extracellular Acidification Rate (ECAR) using the Seahorse Extracellular Flux Analyzer (Fig. 7F-L). DOX induced decreases in basal respiration by $\sim 63 \%$ for $0.5 \mu \mathrm{M}$ DOX and by $\sim 47 \%$ for $1 \mu \mathrm{M}$ DOX (Fig. 8G), in maximal respiration by $\sim 68 \%$ for $0.5 \mu \mathrm{M}$ DOX and by $\sim 74 \%$ for $1 \mu \mathrm{M}$ DOX (Fig. $8 \mathrm{H}$ ), and in basal acidification by $\sim 74 \%$ for
$0.5 \mu \mathrm{M}$ DOX and by $\sim 61 \%$ for $1 \mu \mathrm{M}$ DOX (Fig. 8G). Basal acidification reflects the activity of several components, including lactic production by glycolysis and TCA cycle. In an attempt to reverse this effect, cells were pre-treated with the PDK inhibitor DCA, in order to decrease PDH phosphorylation by PDKs and improve its activity. DCA $(3 \mathrm{mM})$ pretreatment partially inhibited the negative effects of DOX on ATP levels, recovering $\sim 14 \%$ of the lost ATP levels for $0.5 \mu \mathrm{M}$ DOX and $\sim 16 \%$ for $1 \mu \mathrm{M}$ DOX (Fig. 7E). No protection was observed for $1 \mathrm{mM}$ DCA (data not shown). Pre-treatment with $3 \mathrm{mM}$ DCA ameliorated the loss of basal $(\sim 17 \%)$ and maximal $(\sim 12 \%)$ respirations in cells incubated with $0.5 \mu \mathrm{M}$ DOX, but not with $1 \mu \mathrm{M}$ DOX (Fig. $7 \mathrm{G}, \mathrm{H}$ ), suggesting that the loss of PDH activity partially contributes to bioenergetic dysfunction associated with DOX cardiotoxicity and may be reversible for lower doses of this drug. DCA pre-treatment also decreased the loss of basal acidification in cells incubated with $0.5 \mu \mathrm{M}$ DOX ( $\sim 13 \%)$ (Fig. 7I). To better understand the energetic shifts induced by DOX and DCA treatments, and the impact in the capacity of cells to respond to mitochondrial stress, the Seahorse results are also shown in the form of energy maps (Fig. 7J-L). In a control situation, Cor.At cells responded 

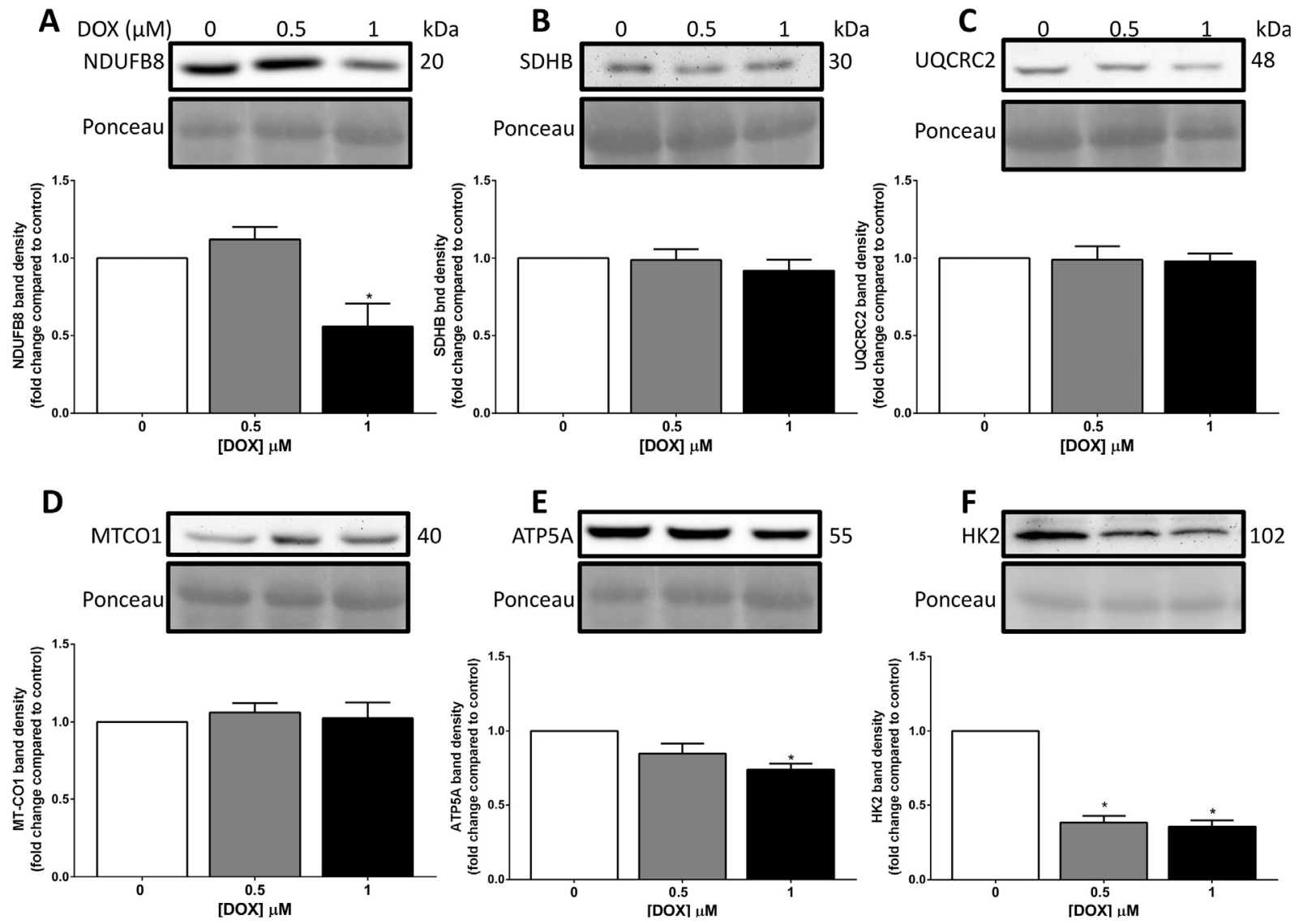

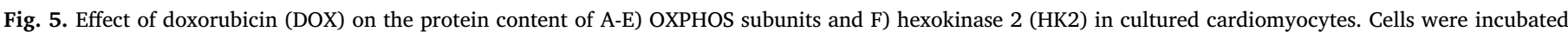

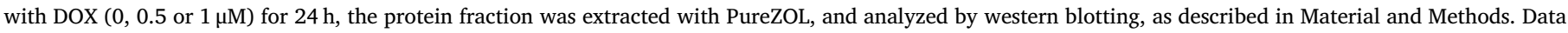
are the mean \pm SEM from 4 independent experiments. ${ }^{*} \mathrm{p}<0.05$ compared to control.

to mitochondrial stress induced by acute FCCP + oligomycin exposure by adopting a more pseudo-energetic phenotype, with increased OCR and ECAR (Fig. 7J). DOX-treated cells presented decreased ECAR and OCR, becoming more energetically quiescent. DCA pre-treatment had different effects in cells exposed to the two DOX concentrations. To facilitate the visualization, zoomed energy maps corresponding to $0.5 \mu \mathrm{M}$ DOX (Fig. 7K), and $1 \mu \mathrm{M}$ DOX (Fig. $7 \mathrm{~L}$ ) conditions are also presented. Acute mitochondrial stress by exposure to FCCP + oligomycin induced a transition to a more pseudo-energetic phenotype in cells exposed to $0.5 \mu \mathrm{M}$ DOX, but cells exposed to $1 \mu \mathrm{M}$ DOX became more energetically quiescent after this acute mitochondrial stress. Pretreatment with DCA induced a transition to a more energetic phenotype in cells exposed to $0.5 \mu \mathrm{M}$ DOX, whereas cells exposed to $1 \mu \mathrm{M}$ DOX seemed to become more aerobic.

The results are summarized in Fig. 8.

\section{Discussion}

DOX is a widely used anticancer drug whose clinically used dosages are limited by delayed cardiotoxicity. DOX cardiotoxicity has been studied in in vivo and in vitro models, including the H9c2 rat cardiomyoblast cell line (Sardao et al., 2009a; Branco et al., 2012; Moreira et al., 2014; Deus et al., 2015; Sampaio et al., 2016) However, cardiac cells that maintain the capacity to beat in culture, such as Cor.At mouse iPSC-derived cardiomyocytes, may represent a better in vitro model to further uncover the mechanisms of DOX-induced cardiotoxicity.

Mouse stem cell-derived cardiomyocytes have been a useful tool for toxicity screening assays of compounds interfering with ion channels function, contractility and cardiomyocyte metabolism (Himmel, 2013; Lagerqvist et al., 2015). However, these cells may still present critical differences compared to their human counterparts, due to species specificities in cardiomyocyte function (Rajamohan et al., 2013) which demand caution when extrapolating our results to clinical applications. Physiological and biochemical differences between mouse and human cardiomyocyte function include a $\sim 10$ times faster beat rate in the mouse, dissimilar ion channel-mediated repolarization and phospholamban regulatory roles, as well as in the expression and location of structural proteins (Rajamohan et al., 2013). Nonetheless, the presence of the contractile component in iPSCs-derived mouse cardiomyocytes makes these cells more bioenergetically demanding compared to other commonly used non-contractile models of cardiac cells, including H9c2 cardiomyoblasts, thus allowing a more sensitive detection of mitochondrial drug liabilities.

The objective of this work was to investigate the mechanisms underlying DOX toxicity in beating cardiomyocytes, focusing on mitochondria stress-related and metabolic pathways. For this purpose, we used Cor.At cardiomyocytes treated with 0.5 or $1 \mu \mathrm{M} \mathrm{DOX}$, and investigated the morphological, functional and biochemical changes associated with mitochondrial bioenergetics, DNA-damage response and apoptosis. These concentrations fall within the range found in plasma of patients administered DOX (Greene et al., 1983) and are thus clinically relevant.

DOX induced dose-dependent alterations in cell morphology and ATP levels without affecting total cell mass. The higher DOX concentration induced a decrease in nuclear area, consistent with apoptotic nuclear pyknosis, contrary to what was observed in H9c2 cells, in which DOX induced nuclear hypertrophy (Sardao et al., 2009b). Morphological changes accompanied alterations in mitochondrial polarization, and chromatin condensation and fragmentation. At the lower concentration, DOX induced the appearance of a few apoptotic nuclei and 
A

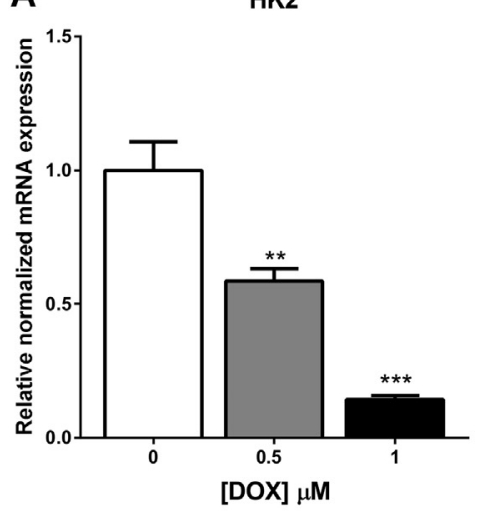

B

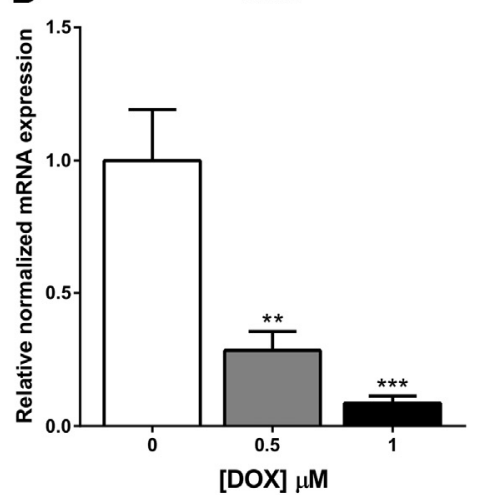

C

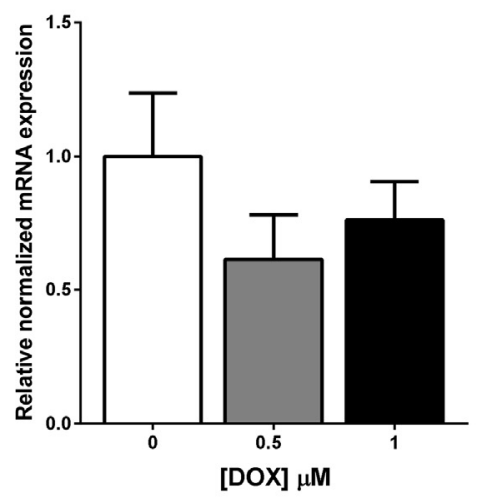

D

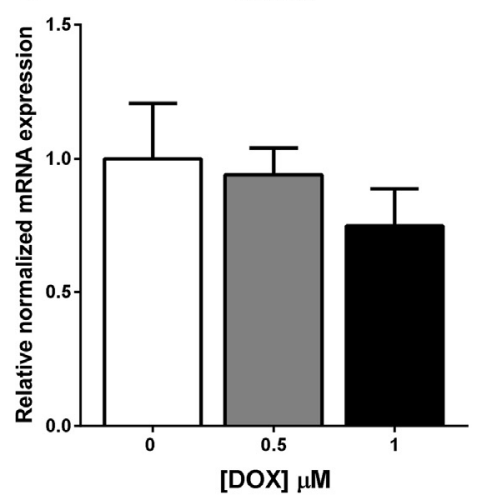

E

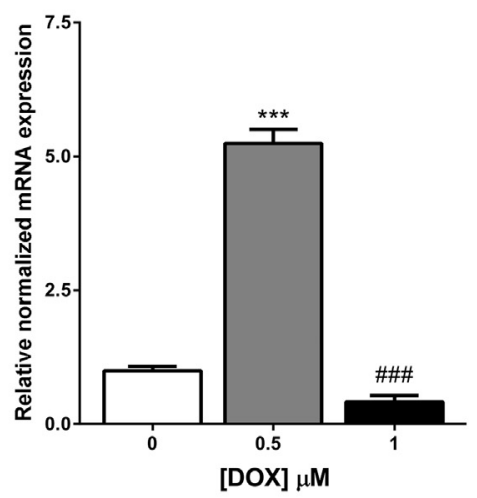

$\mathbf{F}$

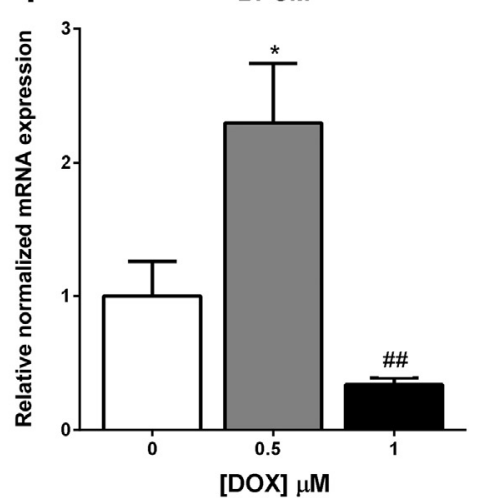

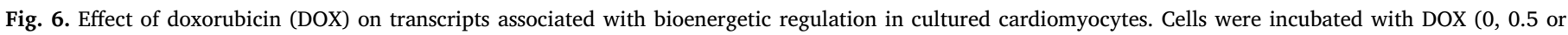

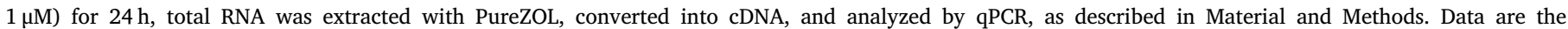

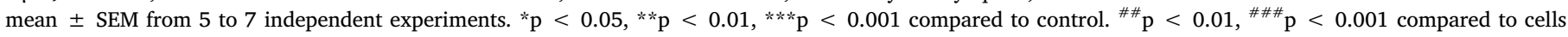
treated with $0.5 \mu \mathrm{M}$ DOX.

seemed to increase perinuclear mitochondrial polarization, which can be an early feature of apoptosis (Sanchez-Alcazar et al., 2000; Giovannini et al., 2002; Iijima et al., 2003; Liu et al., 2005; Cao et al., 2007; Silva et al., 2016). Electrophysiologically, DOX has previously been reported to affect beat period, spike amplitude and corrected field potential duration in a time and dose-dependent manner (Abassi et al., 2012; Koci et al., 2017). A 24 h DOX exposure in human iPSC-derived cardiomyocytes induced arrhythmic beating at $10 \mu \mathrm{M}$ DOX and caused a complete arrest of heart beating at $100 \mu \mathrm{M}$ (Koci et al., 2017). Interestingly, DOX showed both acute and chronic electrophysiological effects with abnormal beating patterns worsening with prolonged time after treatment (Maillet et al., 2016). In our model, and in line with these previous studies, DOX $(0.5$ and $1 \mu \mathrm{M})$ did not have a major impact on cardiomyocytes beating for the $24 \mathrm{~h}$ exposure (Supplementary Videos 1-3), however, the beating stopped completely when cells were exposed to DOX for $48 \mathrm{~h}$.

Under these conditions, the activities of caspases -9 and $-3 / 7$ were also significantly increased. At the highest DOX concentration, an increase in apoptotic nuclei and a decrease in mitochondrial polarization, together with increased activities of caspases -9 and $-3 / 7$, and increased protein content of the caspase- 3 cleavage-resulting PARP-1 fragment were observed. These results suggest the involvement of the mitochondrial apoptotic pathway and are in accordance with previous studies from our group in different biological models (Sardao et al., 2009a; Ascensao et al., 2011; Moreira et al., 2014; Deus et al., 2015).

Both DOX concentrations used in this work induced an increase in p53 and a decrease in SOD2 protein contents. The transcription factor p53 is sensitive to redox changes and coordinates multiple cell responses including the decision between cell survival and cell death, namely through the blockade of cell cycle progression in response to DNA damage (Vousden and Ryan, 2009). The levels of p53 protein increase after exposure to stress signals, and it may act through transcription-dependent and independent mechanisms, namely regulating mitochondrial apoptotic signaling (Speidel, 2010).

Transcriptional regulation by $\mathrm{p} 53$ activates or represses the transcription of target genes (Riley et al., 2008). However, the transcriptional response of p53 is transient, primarily through the induction of short-lived mRNAs (Melanson et al., 2011). Transcription-mediated effects involve upregulation of pro-apoptotic genes, such as Puma, Noxa and Bax, and downregulation of anti-apoptotic genes, such as Bcl-2 (Riley et al., 2008). Transcription-independent effects include direct interaction with Bax (Chipuk et al., 2004) or with SOD2 (Robbins and Zhao, 2012; Candas and Li, 2014). The latter interaction leads to a reduction of superoxide anion scavenging activity, with a subsequent decrease in mitochondrial membrane potential and activation of apoptosis (Robbins and Zhao, 2012; Candas and Li, 2014). However, transcription-mediated effects may also be in place, since it was described that p53 represses SOD2 gene expression (Drane et al., 2001). DOX effects on SOD2 protein amount and activity seem to be dependent on the experimental model, dose and duration of DOX treatment. Subchronic DOX exposure decreased SOD2 activity in rat hearts (Marques-Aleixo et al., 2015), while acute DOX exposure induced an increase in SOD2 activity (Ascensao et al., 2011). Differential effects of DOX in SOD2 content observed across different experimental models may be related with the fact that p53 can both suppress and induce SOD2 expression, depending on the balance of promoter and enhancer 
A

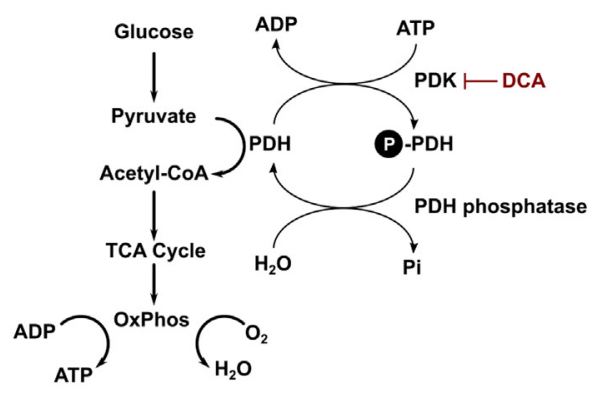

B

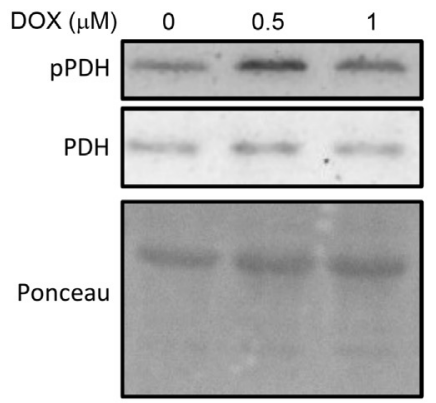

E
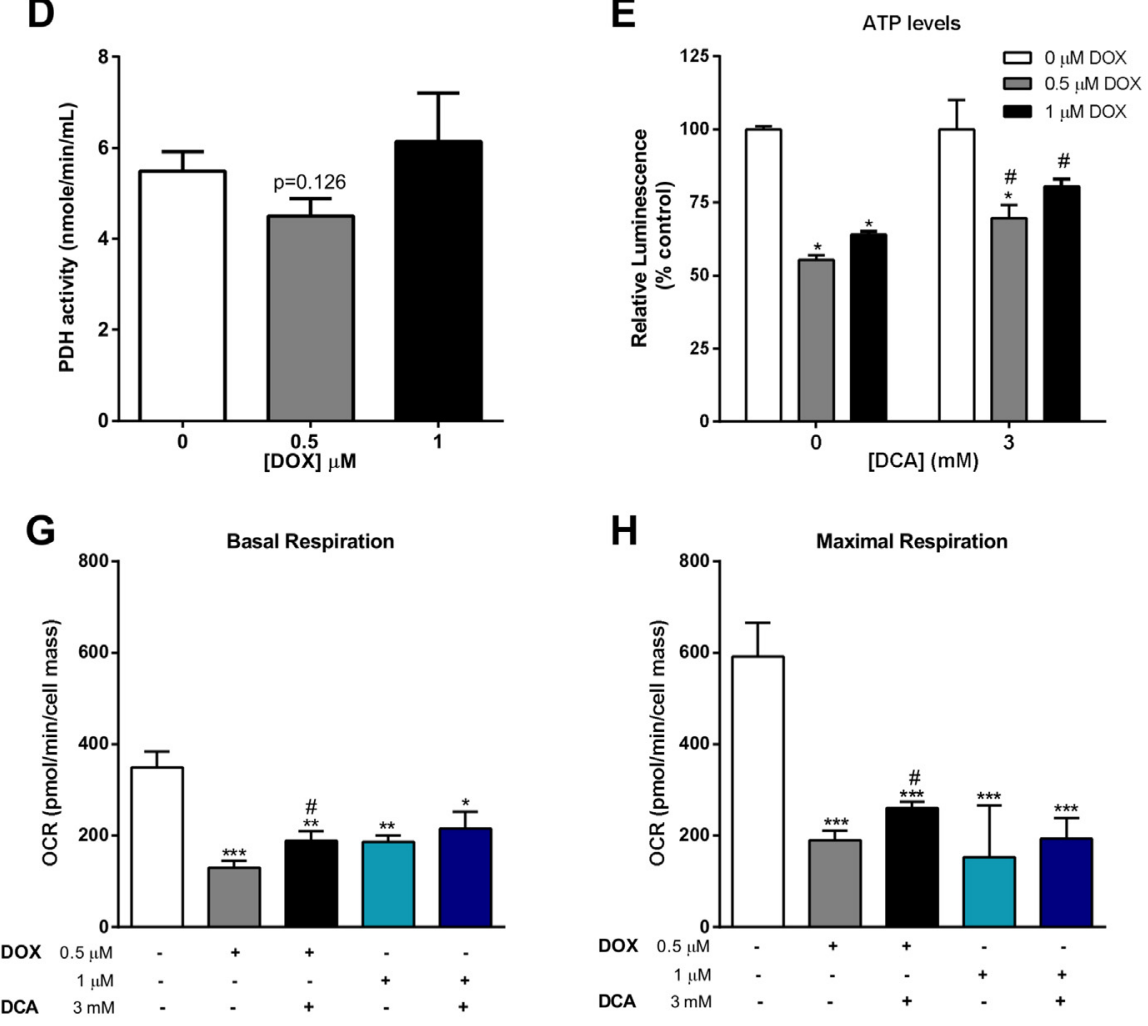
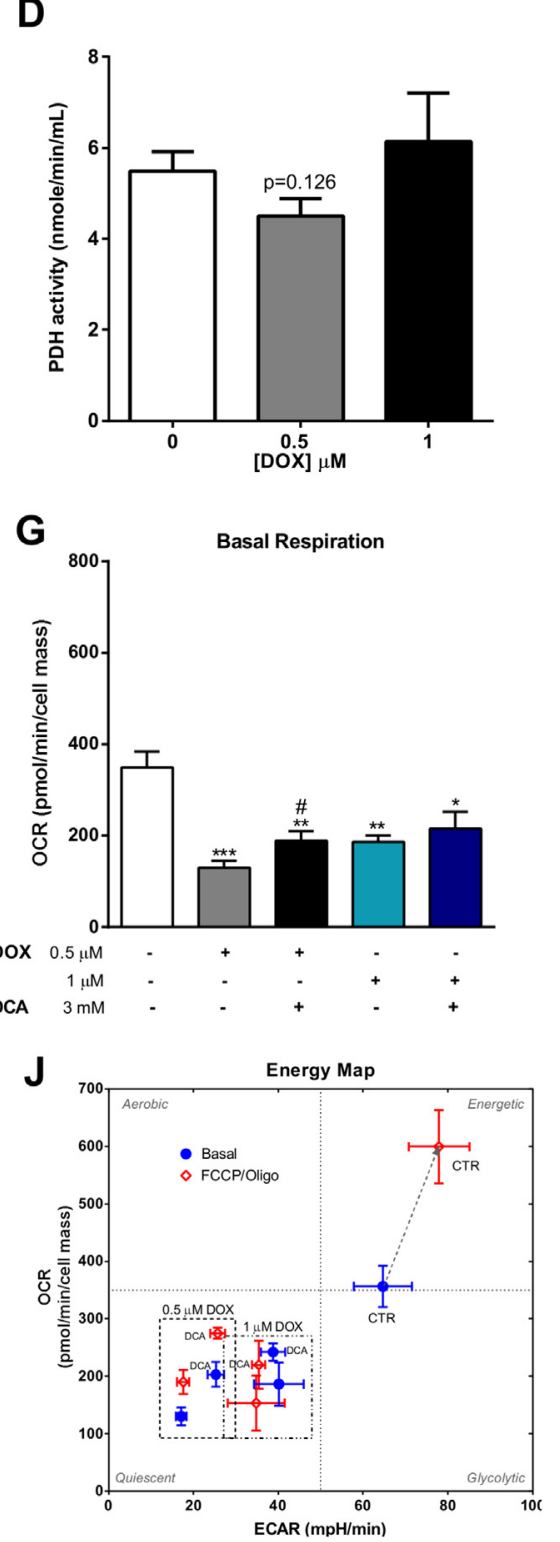

H

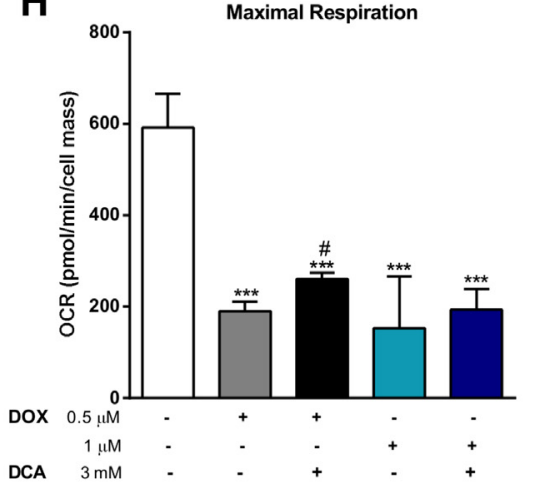

K

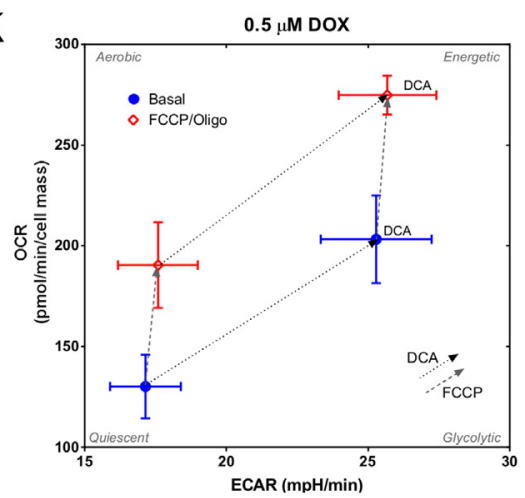

C

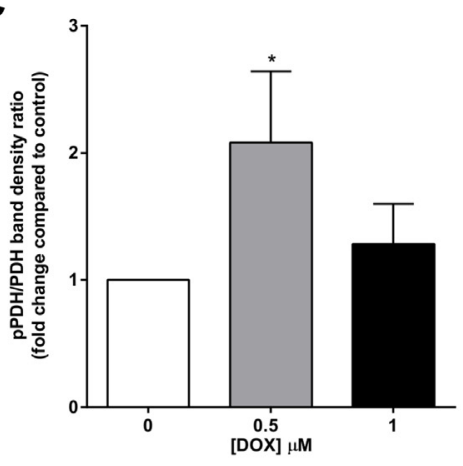

$\mathbf{F}$

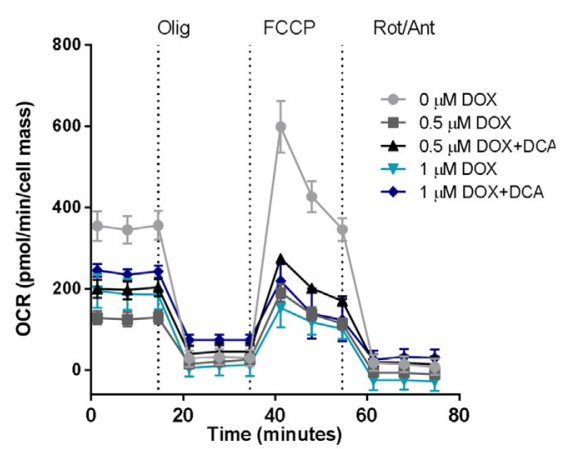

I

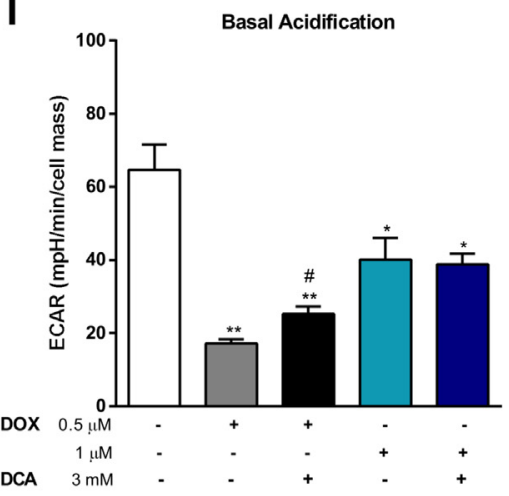

$\mathbf{L}$

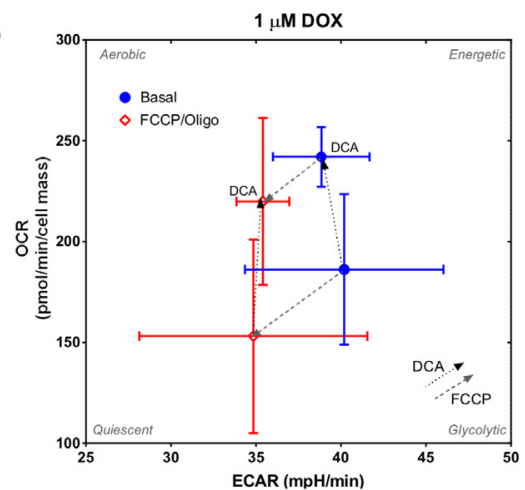

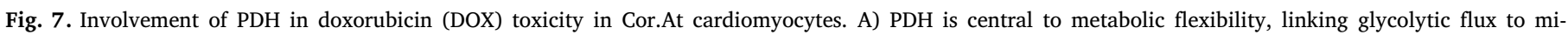

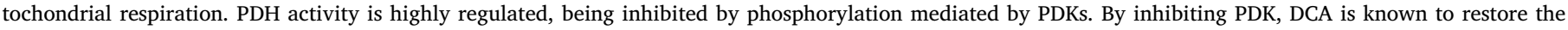

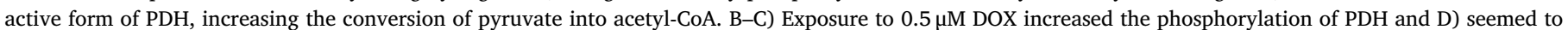

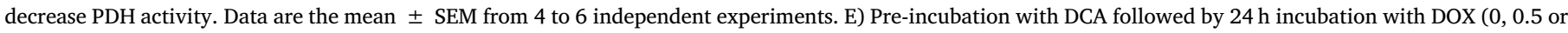

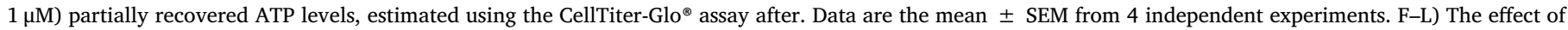

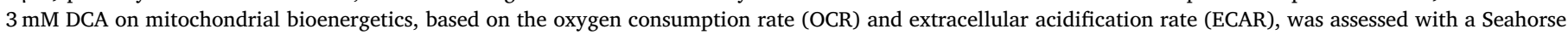

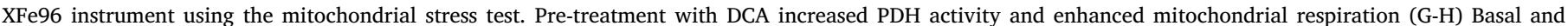

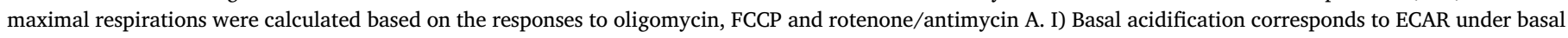

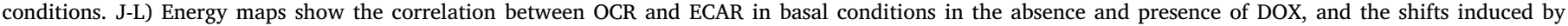

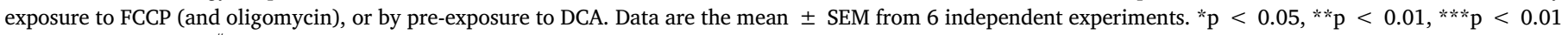
compared to control. ${ }^{*} \mathrm{p}<0.05$ compared to cells treated only with $0.5 \mu \mathrm{M}$ DOX. 


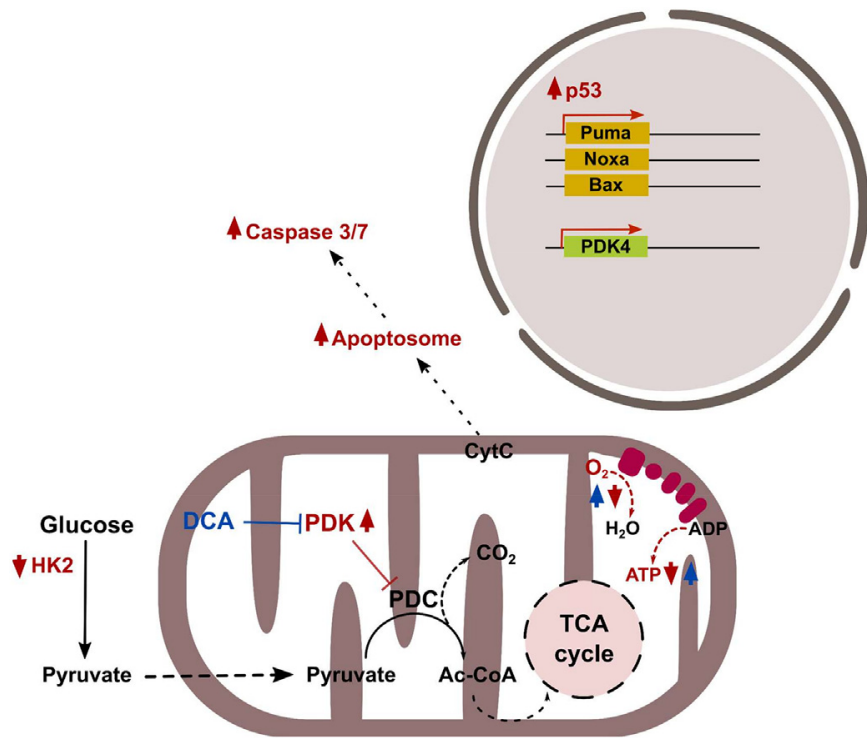

Fig. 8. DOX treatment leads to p53-associated caspase activation and apoptosis, decreased HK2 levels and reduced mitochondrial respiration (red) in Cor.AT cardiomyocytes. Cells treated with $0.5 \mu \mathrm{M}$ DOX presented increased PDK4 transcripts, followed by increased $\mathrm{PDH}$ phosphorylation and inactivation (red). DCA, an inhibitor of PDK, ameliorated the impact of DOX treatment by activating $\mathrm{PDH}$ and partially restoring mitochondrial respiration and ATP levels (blue). (For interpretation of the references to color in this figure legend, the reader is referred to the web version of this article.)

binding transcription factors, and SOD2 activity may also affect p53 activation (Dhar et al., 2010).

Activation of caspases by DOX was completely prevented by preincubation with the non-selective caspase inhibitor z-VAD-fmk. Moreover, pre-exposure to $\mathrm{Pf} \alpha$, a p53 inactivator that blocks p53-dependent transcriptional activation and apoptosis (Komarov et al., 1999), partially prevented caspase- 9 activation by DOX at $1 \mu \mathrm{M}$, and completely prevented caspase $3 / 7$ activation by DOX at 0.5 and $1 \mu \mathrm{M}$. Pfa per se showed a tendency to increase caspase- 9 activity, which may explain why no protection was observed for the lower DOX concentration, contrary to what was observed in H9c2 cells (Sardao et al., 2009a). In addition, the antioxidant NAC did not significantly protect against DOX-induced caspase activation in this cell model. In our study, DOX increased p53-associated caspase activity and decreased SOD2 content, although increased ROS generation did not seem to occur upstream of caspase activation. The present results further reinforce the role of p53 in DOX-induced activation of caspases-3 and -9 in cardiomyocytes, as previously measured in H9c2 cardiomyoblasts by our group (Sardao et al., 2009a), suggesting that DOX-induced p53-mediated cytotoxicity is common for both H9c2 cardiomyoblasts, which show proliferative activity, and the cells used in the present study, which do not proliferate in culture.

In accordance with the increase in p53 protein content and apoptotic hallmarks, DOX dose-dependently affected p53 target transcripts associated with mitochondria-dependent apoptosis and DNA-damage response. Nuclear-localized p53 activates genes that arrest cell growth and repair DNA damage, such as Atm, Atr, Chk1, Chk2, Cdk1 and Cdk2 (Riley et al., 2008; Zannini et al., 2014). At the higher DOX concentration, a significant decrease in Cdk1, Atr and Chk2 transcripts was observed, whereas at the lower concentration there was an increase in Mdm2, Puma, Noxa and Bax transcripts, and a decrease in Bcl-2 and Chk1. These results suggest that cells responded to DOX-induced DNA damage through activation of p53 transcriptional activity, which led to mitochondrial-mediated apoptosis, in a dose-dependent manner.

In the present work, DOX treatment altered proteins and transcripts associated with mitochondrial bioenergetics and decreased ATP levels and basal and maximal oxygen consumption rates. At the higher DOX concentration, a decrease in protein content of Complex I and ATP synthase subunits and HK2 was observed, together with a significant decrease in Hk2 transcripts. Complex I and ATP synthase activity and/ or protein expression were also previously shown to be decreased in DOX-exposed animals (Ascensao et al., 2011; Marques-Aleixo et al., 2015). At the lower concentration, there was a decrease in Hk2 and Hif1-alpha transcripts and an increase in Pdk4 and Bpgm transcripts. For the higher DOX concentration, there was a significant decrease in Hk2 and Hif1a transcripts. Increases in transcripts observed with the lower DOX concentration were generally not seen for the higher DOX concentration, probably due to the higher rate of apoptosis observed. In previous studies with mice exposed to a single dose of DOX, genes related to glucose metabolism, including Hk2, Pdk4, fructose-2,6-bisphosphate 2-phosphatase, and especially Bpgm, were suggested to be involved in DOX-induced cardiac injury (Wei et al., 2015). HK2, BPGM, and PDK4 are rate-limiting enzymes that control glucose metabolism (Stryer, 2015). Since DOX administration has been shown to significantly decrease glucose and ATP levels in the heart (Wei et al., 2015), these metabolic genes may be involved in the regulation of glucose metabolism and energy generation, contributing to remodel heart metabolism in the presence of that anthracycline.

In the present study, the decrease in HK2 levels observed after incubation with both DOX concentrations may result in a decrease in the glycolytic rate, which could contribute to the observed decrease in basal acidification rate measured by using the Extracellular Flux Analyzer. HK2 is primarily expressed in skeletal and cardiac muscles and is regulated by insulin or ischemia (Calmettes et al., 2015). Hexokinases regulate the use of glucose for catabolic processes, regulate reduced-glutathione levels through generation of NADPH, and modulate cell death by interacting with the voltage-dependent anion channel (VDAC), which is a regulator of the mitochondrial permeability transition pore (Calmettes et al., 2015). Modulation of HK2 levels alters cardiomyocyte energy levels and contractility (Wu et al., 2011). Decrease in HK2 levels results in decreased cardiac function and altered remodeling after ischemia/reperfusion injury (Wu et al., 2011) and HK2 knockdown resulted in exaggerated cardiac hypertrophy through increased ROS production (Wu et al., 2012). In contrast, overexpression of HK2 increases both ATP levels and $\mathrm{O}_{2}$ consumption in cardiomyocytes, as well as cellular contractility (Wu et al., 2011).

Hif1a has been shown to be significantly downregulated in hearts of mice exposed to DOX (Wei et al., 2015). Hypoxia and HIF-1 increase virtually all the enzymes in the glycolytic pathway, including HK2, as well as glucose transporters (Ke and Costa, 2006). Thus, the observed decrease in the levels of Hifla transcripts is in agreement with the decrease in HK2 protein and transcript levels, and with the decrease in basal acidification rate, and our results suggest a concerted cellular response to decrease glucose consumption after DOX exposure, which may result from a metabolic remodeling or from lower energetic demands of treated cells.

BPGM is an enzyme known to regulate hemoglobin oxygen affinity in erythrocytes and placental cells. It participates in glycolysis by converting 1,3-bisphosphoglycerate (1,3-BPG) to 2,3-bisphosphoglycerate (2,3-BPG), which acts as an allosteric effector influencing oxygen and hemoglobin dissociation curve, especially in erythrocytes (Cho et al., 2008). This enzyme is expressed in various tissues and cells, including the heart. BPGM was previously suggested to play a central role in DOX-induced cardiac injury (Wei et al., 2015). Although the role of BPGM in cardiovascular diseases including DOX-induced cardiotoxicity remains unclear, the protein levels of BPGM were found to be significantly decreased after DOX administration in the heart and in cultured cardiomyocytes, consistently with our results for the higher DOX concentration, suggesting that BPGM may play a core role in DOXinduced cardiomyopathy (Wei et al., 2015).

PDK4 regulates the metabolic flux between glycolysis and mitochondrial OXPHOS by phosphorylating and inactivating pyruvate 
dehydrogenase (PDH), resulting in decreased conversion of pyruvate into acetyl-CoA (Patel and Korotchkina, 2006), conserving glucose and promoting fatty acid oxidation (FAO) (Sugden et al., 2000). DOX was previously shown to upregulate the expression of FoxO1 in H9c2 cells (Liu et al., 2016) and FoxO1 and FoxO3 in rat hearts (Kavazis et al., 2014), which are known to mediate PDK4 upregulation (Puthanveetil et al., 2010; Piao et al., 2013; Puthanveetil et al., 2013). Since cardiomyocytes have high energy demands, failure to oxidize enough carbohydrates leads to cardiac inefficiency (Zhang et al., 2014). Transgenic mice overexpressing PDK4 in the heart present decreased glucose catabolism and increased FAO, suggesting that increased cardiac PDK expression is sufficient to promote a loss in metabolic flexibility and exacerbate cardiomyopathy (Zhao et al., 2008). A metabolic shift to FAO would require active complex I, which is known to be compromised by DOX treatment (Davies and Doroshow, 1986; Oliveira et al., 2004). In addition, for cells in culture to be able to shift their metabolism to increased FAO, fatty acids would have to be available in the culture medium or in intracellular storages. In our conditions, the increase in PDK4 levels seems to contribute to PDH inactivation. In the presence of DOX, cells seem to suffer a generalized bioenergetic failure.

Pre-treatment with DCA ameliorated the impact of DOX treatment on ATP levels and mitochondrial respiration, suggesting that PDH may be an interesting therapeutic target to avoid DOX cardiotoxic side-effects. Since tumor cells are mostly reliant on glycolysis for energy, activation of PDH may also contribute to improve cancer chemotherapy (Sutendra and Michelakis, 2013; Zhang et al., 2015). However, other strategies to overcome PDH deficiency, besides the use of DCA, may have to be developed, since co-treatment of DOX + DCA may affect the efficacy of anti-tumor chemotherapy (Heshe et al., 2011).

In conclusion, the DOX concentrations used in the present study differentially affected several proteins and transcripts associated with mitochondrial bioenergetics, and induced p53-dependent caspase activation, affecting the expression of p53 target transcripts associated with mitochondria-dependent apoptosis and DNA-damage response. The highest concentration induced a high degree of apoptosis, with increased nuclear apoptotic morphology, PARP-1 cleavage and decrease of some OXPHOS protein subunits. This may be relevant for more severe DOX treatments. Interestingly, cells treated with the lowest DOX concentration seem to be more mildly affected, presenting metabolic remodeling associated with an increase in PDK4 transcript levels, phosphorylation of PDH and downregulation of PDH activity. This led to a decrease in basal and maximal oxygen consumption rates (OCR) and in basal acidification rate, which were partially recovered by pretreatment with the PDK inhibitor DCA.

The results suggest that the higher DOX concentration mainly induces p53-dependent apoptosis, whereas for the lower DOX concentration the cardiotoxic effects involve the adoption of a quiescent energetic phenotype that is improved by indirect stimulation of PDH activity with DCA, unveiling PDH as a possible therapeutic target to ameliorate the effects of DOX cardiotoxicity.

Supplementary data to this article can be found online at https:// doi.org/10.1016/j.taap.2018.04.009.

\section{Acknowledgements}

This work was funded by FEDER funds through the Operational Program for Competitiveness Factors-COMPETE and national funds by FCT-Foundation for Science and Technology under research grant PTDC/DTP-FTO/2433/2014 and UID/NEU/04539/2013. Supported also by QREN project 4832 with reference CENTRO- 07-ST24-FEDER002008 financed through FEDER. TC-O (SFRH/BPD/101169/2014) was supported by a FCT Post-Doctoral fellowship and LF (SFRH/BD/ 52429/2013), ARC (SFRH/BD/103399/2014) and CMD (SFRH/BD/ 100341/2014) were supported by FCT PhD-fellowships.

\section{Conflicts of interest}

The authors have no conflicts of interest to declare.

\section{References}

Abassi, Y.A., Xi, B., Li, N., Ouyang, W., Seiler, A., Watzele, M., Kettenhofen, R., Bohlen, H., Ehlich, A., Kolossov, E., Wang, X., Xu, X., 2012. Dynamic monitoring of beating periodicity of stem cell-derived cardiomyocytes as a predictive tool for preclinical safety assessment. Br. J. Pharmacol. 165, 1424-1441.

Ascensao, A., Lumini-Oliveira, J., Machado, N.G., Ferreira, R.M., Goncalves, I.O., Moreira, A.C., Marques, F., Sardao, V.A., Oliveira, P.J., Magalhaes, J., 2011. Acute exercise protects against calcium-induced cardiac mitochondrial permeability transition pore opening in doxorubicin-treated rats. Clin. Sci. 120, 37-49.

Bakhanashvili, M., Grinberg, S., Bonda, E., Simon, A.J., Moshitch-Moshkovitz, S., Rahav, G., 2008. p53 in mitochondria enhances the accuracy of DNA synthesis. Cell Death Differ. 15, 1865-1874.

Branco, A.F., Sampaio, S.F., Moreira, A.C., Holy, J., Wallace, K.B., Baldeiras, I., Oliveira, P.J., Sardao, V.A., 2012. Differentiation-dependent doxorubicin toxicity on H9c2 cardiomyoblasts. Cardiovasc. Toxicol. 12, 326-340.

Calmettes, G., Ribalet, B., John, S., Korge, P., Ping, P., Weiss, J.N., 2015. Hexokinases and cardioprotection. J. Mol. Cell. Cardiol. 78, 107-115.

Candas, D., Li, J.J., 2014. MnSOD in oxidative stress response-potential regulation via mitochondrial protein influx. Antioxid. Redox Signal. 20, 1599-1617.

Cao, J., Liu, Y., Jia, L., Zhou, H.M., Kong, Y., Yang, G., Jiang, L.P., Li, Q.J., Zhong, L.F., 2007. Curcumin induces apoptosis through mitochondrial hyperpolarization and mtDNA damage in human hepatoma G2 cells. Free Radic. Biol. Med. 43, 968-975.

Carvalho, F.S., Burgeiro, A., Garcia, R., Moreno, A.J., Carvalho, R.A., Oliveira, P.J., 2014 Doxorubicin-induced cardiotoxicity: from bioenergetic failure and cell death to cardiomyopathy. Med. Res. Rev. 34, 106-135.

Cheung, K.G., Cole, L.K., Xiang, B., Chen, K., Ma, X., Myal, Y., Hatch, G.M., Tong, Q., Dolinsky, V.W., 2015. Sirtuin-3 (SIRT3) protein attenuates doxorubicin-induced oxidative stress and improves mitochondrial respiration in H9c2 cardiomyocytes. J. Biol. Chem. 290, 10981-10993.

Chipuk, J.E., Kuwana, T., Bouchier-Hayes, L., Droin, N.M., Newmeyer, D.D., Schuler, M., Green, D.R., 2004. Direct activation of Bax by p53 mediates mitochondrial membrane permeabilization and apoptosis. Science 303, 1010-1014.

Cho, J., King, J.S., Qian, X., Harwood, A.J., Shears, S.B., 2008. Dephosphorylation of 2,3 bisphosphoglycerate by MIPP expands the regulatory capacity of the RapoportLuebering glycolytic shunt. Proc. Natl. Acad. Sci. U. S. A. 105, 5998-6003.

Coelho, A.R., Martins, T.R., Couto, R., Deus, C., Pereira, C.V., Simoes, R.F., Rizvanov, A.A., Silva, F., Cunha-Oliveira, T., Oliveira, P.J., Serafim, T.L., 2017. Berberine-induced cardioprotection and Sirt3 modulation in doxorubicin-treated H9c2 cardiomyoblasts. Biochim. Biophys. Acta 1863, 2904-2923.

Davies, K.J., Doroshow, J.H., 1986. Redox cycling of anthracyclines by cardiac mitochondria. I. Anthracycline radical formation by NADH dehydrogenase. J. Biol. Chem. 261, 3060-3067.

Deus, C.M., Zehowski, C., Nordgren, K., Wallace, K.B., Skildum, A., Oliveira, P.J., 2015. Stimulating basal mitochondrial respiration decreases doxorubicin apoptotic signaling in H9c2 cardiomyoblasts. Toxicology 334, 1-11.

Dhar, S.K., Xu, Y., St Clair, D.K., 2010. Nuclear factor kappaB- and specificity protein 1 dependent p53-mediated bi-directional regulation of the human manganese superoxide dismutase gene. J. Biol. Chem. 285, 9835-9846.

Drane, P., Bravard, A., Bouvard, V., May, E., 2001. Reciprocal down-regulation of p53 and SOD2 gene expression-implication in p53 mediated apoptosis. Oncogene 20, 430-439.

Frank, S., Helm, A., Durante, M., Ritter, S., 2014. Cellular radiation response of mouse embryonic stem cell derived cardiomyocytes. Sci. Rep. 2013 (GSI Helmholtzzentrum für Schwerionenforschung, Darmstadt, pp. 222 p).

Gergely, S., Hegedus, C., Lakatos, P., Kovacs, K., Gaspar, R., Csont, T., Virag, L., 2015. High throughput screening identifies a novel compound protecting cardiomyocytes from doxorubicin-induced damage. Oxidative Med. Cell. Longev. 2015, 178513.

Giovannini, C., Matarrese, P., Scazzocchio, B., Sanchez, M., Masella, R., Malorni, W. 2002. Mitochondria hyperpolarization is an early event in oxidized low-density lipoprotein-induced apoptosis in Caco-2 intestinal cells. FEBS Lett. 523, 200-206.

Greene, R.F., Collins, J.M., Jenkins, J.F., Speyer, J.L., Myers, C.E., 1983. Plasma pharmacokinetics of adriamycin and adriamycinol: implications for the design of in vitro experiments and treatment protocols. Cancer Res. 43, 3417-3421.

Heshe, D., Hoogestraat, S., Brauckmann, C., Karst, U., Boos, J., Lanvers-Kaminsky, C., 2011. Dichloroacetate metabolically targeted therapy defeats cytotoxicity of standard anticancer drugs. Cancer Chemother. Pharmacol. 67, 647-655.

Himmel, H.M., 2013. Drug-induced functional cardiotoxicity screening in stem cell-derived human and mouse cardiomyocytes: effects of reference compounds. J. Pharmacol. Toxicol. Methods 68, 97-111.

Iijima, T., Mishima, T., Akagawa, K., Iwao, Y., 2003. Mitochondrial hyperpolarization after transient oxygen-glucose deprivation and subsequent apoptosis in cultured rat hippocampal neurons. Brain Res. 993, 140-145.

Kavazis, A.N., Smuder, A.J., Powers, S.K., 2014. Effects of short-term endurance exercise training on acute doxorubicin-induced FoxO transcription in cardiac and skeletal muscle. J. Appl. Physiol. 117, 223-230.

Ke, Q., Costa, M., 2006. Hypoxia-inducible factor-1 (HIF-1). Mol. Pharmacol. 70, 1469-1480.

Koci, B., Luerman, G., Duenbostell, A., Kettenhofen, R., Bohlen, H., Coyle, L., Knight, B., Ku, W., Volberg, W., Woska Jr., J.R., Brown, M.P., 2017. An impedance-based 
approach using human iPSC-derived cardiomyocytes significantly improves in vitro prediction of in vivo cardiotox liabilities. Toxicol. Appl. Pharmacol. 329, 121-127.

Kolossov, E., Lu, Z., Drobinskaya, I., Gassanov, N., Duan, Y., Sauer, H., Manzke, O., Bloch, W., Bohlen, H., Hescheler, J., Fleischmann, B.K., 2005. Identification and characterization of embryonic stem cell-derived pacemaker and atrial cardiomyocytes. FASEB J. 19, 577-579.

Kolossov, E., Bostani, T., Roell, W., Breitbach, M., Pillekamp, F., Nygren, J.M., Sasse, P., Rubenchik, O., Fries, J.W., Wenzel, D., Geisen, C., Xia, Y., Lu, Z., Duan, Y., Kettenhofen, R., Jovinge, S., Bloch, W., Bohlen, H., Welz, A., Hescheler, J., Jacobsen, S.E., Fleischmann, B.K., 2006. Engraftment of engineered ES cell-derived cardiomyocytes but not BM cells restores contractile function to the infarcted myocardium. J. Exp. Med. 203, 2315-2327.

Komarov, P.G., Komarova, E.A., Kondratov, R.V., Christov-Tselkov, K., Coon, J.S., Chernov, M.V., Gudkov, A.V., 1999. A chemical inhibitor of p53 that protects mice from the side effects of cancer therapy. Science 285, 1733-1737.

Lagerqvist, E.L., Finnin, B.A., Elliott, D.A., Anderson, D.J., Wu, S.M., Pouton, C.W., Haynes, J.M., 2015. Comparing mouse and human pluripotent stem cell derived cardiac cells: both systems have advantages for pharmacological and toxicological screening. J. Pharmacol. Toxicol. Methods 74, 17-25.

Li, D., Li, J., An, Y., Yang, Y., Zhang, S.Q., 2013. Doxorubicin-induced apoptosis in H9c2 cardiomyocytes by NF-kappaB dependent PUMA upregulation. Eur. Rev. Med. Pharm. Sci. 17, 2323-2329.

Liu, M.J., Yue, P.Y., Wang, Z., Wong, R.N., 2005. Methyl protodioscin induces G2/M arrest and apoptosis in K562 cells with the hyperpolarization of mitochondria. Cancer Lett. 224, 229-241.

Liu, M.H., Shan, J., Li, J., Zhang, Y., Lin, X.L., 2016. Resveratrol inhibits doxorubicininduced cardiotoxicity via sirtuin 1 activation in $\mathrm{H} 9 \mathrm{c} 2$ cardiomyocytes. Exp. Ther. Med. 12, 1113-1118.

Lou, Y., Wang, Z., Xu, Y., Zhou, P., Cao, J., Li, Y., Chen, Y., Sun, J., Fu, L., 2015. Resveratrol prevents doxorubicin-induced cardiotoxicity in H9c2 cells through the inhibition of endoplasmic reticulum stress and the activation of the Sirt1 pathway. Int. J. Mol. Med. 36, 873-880.

Maillet, A., Tan, K., Chai, X., Sadananda, S.N., Mehta, A., Ooi, J., Hayden, M.R., Pouladi, M.A., Ghosh, S., Shim, W., Brunham, L.R., 2016. Modeling doxorubicin-induced cardiotoxicity in human pluripotent stem cell derived-cardiomyocytes. Sci. Rep. 6, 25333

Marques-Aleixo, I., Santos-Alves, E., Mariani, D., Rizo-Roca, D., Padrao, A.I., RochaRodrigues, S., Viscor, G., Torrella, J.R., Ferreira, R., Oliveira, P.J., Magalhaes, J., Ascensao, A., 2015. Physical exercise prior and during treatment reduces sub-chronic doxorubicin-induced mitochondrial toxicity and oxidative stress. Mitochondrion 20, 22-33.

Melanson, B.D., Bose, R., Hamill, J.D., Marcellus, K.A., Pan, E.F., McKay, B.C., 2011. The role of mRNA decay in p53-induced gene expression. RNA 17, 2222-2234.

Minotti, G., Menna, P., Salvatorelli, E., Cairo, G., Gianni, L., 2004. Anthracyclines: molecular advances and pharmacologic developments in antitumor activity and cardiotoxicity. Pharmacol. Rev. 56, 185-229.

Moreira, A.C., Branco, A.F., Sampaio, S.F., Cunha-Oliveira, T., Martins, T.R., Holy, J., Oliveira, P.J., Sardao, V.A., 2014. Mitochondrial apoptosis-inducing factor is involved in doxorubicin-induced toxicity on H9c2 cardiomyoblasts. Biochim. Biophys. Acta 1842, 2468-2478.

Oliveira, P.J., Wallace, K.B., 2006. Depletion of adenine nucleotide translocator protein in heart mitochondria from doxorubicin-treated rats-relevance for mitochondrial dysfunction. Toxicology 220, 160-168.

Oliveira, P.J., Bjork, J.A., Santos, M.S., Leino, R.L., Froberg, M.K., Moreno, A.J., Wallace, K.B., 2004. Carvedilol-mediated antioxidant protection against doxorubicin-induced cardiac mitochondrial toxicity. Toxicol. Appl. Pharmacol. 200, 159-168.

Patel, M.S., Korotchkina, L.G., 2006. Regulation of the pyruvate dehydrogenase complex. Biochem. Soc. Trans. 34, 217-222.

Pereira, G.C., Pereira, S.P., Pereira, C.V., Lumini, J.A., Magalhaes, J., Ascensao, A., Santos, M.S., Moreno, A.J., Oliveira, P.J., 2012. Mitochondrionopathy phenotype in doxorubicin-treated Wistar rats depends on treatment protocol and is cardiac-specific. PLoS One 7, e38867.

Pereira, G.C., Pereira, S.P., Tavares, L.C., Carvalho, F.S., Magalhaes-Novais, S., Barbosa, I.A., Santos, M.S., Bjork, J., Moreno, A.J., Wallace, K.B., Oliveira, P.J., 2016. Cardiac cytochrome c and cardiolipin depletion during anthracycline-induced chronic depression of mitochondrial function. Mitochondrion 30, 95-104.

Piao, L., Sidhu, V.K., Fang, Y.H., Ryan, J.J., Parikh, K.S., Hong, Z., Toth, P.T., Morrow, E., Kutty, S., Lopaschuk, G.D., Archer, S.L., 2013. FOXO1-mediated upregulation of pyruvate dehydrogenase kinase-4 (PDK4) decreases glucose oxidation and impairs right ventricular function in pulmonary hypertension: therapeutic benefits of dichloroacetate. J. Mol. Med. 91, 333-346.

Puthanveetil, P., Wang, Y., Wang, F., Kim, M.S., Abrahani, A., Rodrigues, B., 2010. The increase in cardiac pyruvate dehydrogenase kinase- 4 after short-term dexamethasone is controlled by an Akt-p38-forkhead box other factor-1 signaling axis. Endocrinology 151, 2306-2318.

Puthanveetil, P., Wan, A., Rodrigues, B., 2013. FoxO1 is crucial for sustaining cardiomyocyte metabolism and cell survival. Cardiovasc. Res. 97, 393-403.
Rajamohan, D., Matsa, E., Kalra, S., Crutchley, J., Patel, A., George, V., Denning, C., 2013. Current status of drug screening and disease modelling in human pluripotent stem cells. BioEssays 35, 281-298.

Riley, T., Sontag, E., Chen, P., Levine, A., 2008. Transcriptional control of human p53regulated genes. Nat. Rev. Mol. Cell Biol. 9, 402-412.

Robbins, D., Zhao, Y., 2012. Oxidative stress induced by MnSOD-p53 interaction: pro- or anti-tumorigenic? J. Signal Transduct. 2012, 101465.

Romero-Calvo, I., Ocon, B., Martinez-Moya, P., Suarez, M.D., Zarzuelo, A., MartinezAugustin, O., de Medina, F.S., 2010. Reversible Ponceau staining as a loading control alternative to actin in Western blots. Anal. Biochem. 401, 318-320.

Sampaio, S.F., Branco, A.F., Wojtala, A., Vega-Naredo, I., Wieckowski, M.R., Oliveira, P.J., 2016. p66Shc signaling is involved in stress responses elicited by anthracycline treatment of rat cardiomyoblasts. Arch. Toxicol. 90, 1669-1684.

Sanchez-Alcazar, J.A., Ault, J.G., Khodjakov, A., Schneider, E., 2000. Increased mitochondrial cytochrome c levels and mitochondrial hyperpolarization precede camptothecin-induced apoptosis in Jurkat cells. Cell Death Differ. 7, 1090-1100.

Sardao, V.A., Oliveira, P.J., Holy, J., Oliveira, C.R., Wallace, K.B., 2009a. Doxorubicininduced mitochondrial dysfunction is secondary to nuclear p53 activation in H9c2 cardiomyoblasts. Cancer Chemother. Pharmacol. 64, 811-827.

Sardao, V.A., Oliveira, P.J., Holy, J., Oliveira, C.R., Wallace, K.B., 2009b. Morphological alterations induced by doxorubicin on $\mathrm{H} 9 \mathrm{c} 2$ myoblasts: nuclear, mitochondrial, and cytoskeletal targets. Cell Biol. Toxicol. 25, 227-243.

Severs, N.J., Coppen, S.R., Dupont, E., Yeh, H.I., Ko, Y.S., Matsushita, T., 2004. Gap junction alterations in human cardiac disease. Cardiovasc. Res. 62, 368-377.

Silva, A.M., Barbosa, I.A., Seabra, C., Beltrao, N., Santos, R., Vega-Naredo, I., Oliveira, P.J., Cunha-Oliveira, T., 2016. Involvement of mitochondrial dysfunction in nefazodone-induced hepatotoxicity. Food Chem. Toxicol. 94, 148-158.

Solem, L.E., Wallace, K.B., 1993. Selective activation of the sodium-independent, cy closporin A-sensitive calcium pore of cardiac mitochondria by doxorubicin. Toxicol. Appl. Pharmacol. 121, 50-57.

Speidel, D., 2010. Transcription-independent p53 apoptosis: an alternative route to death. Trends Cell Biol. 20, 14-24.

Stindt, M.H., Carter, S., Vigneron, A.M., Ryan, K.M., Vousden, K.H., 2011. MDM2 promotes SUMO-2/3 modification of p53 to modulate transcriptional activity. Cell Cycle $10,3176-3188$.

Stryer, J.M.B.J.L.T.G.J.G.J.L., 2015. Biochemistry. W. H. Freeman.

Sugden, M.C., Kraus, A., Harris, R.A., Holness, M.J., 2000. Fibre-type specific modification of the activity and regulation of skeletal muscle pyruvate dehydrogenase kinase (PDK) by prolonged starvation and refeeding is associated with targeted regulation of PDK isoenzyme 4 expression. Biochem. J. 346 (Pt 3), 651-657.

Sutendra, G., Michelakis, E.D., 2013. Pyruvate dehydrogenase kinase as a novel therapeutic target in oncology. Front. Oncol. 3, 38.

Vaseva, A.V., Moll, U.M., 2009. The mitochondrial p53 pathway. Biochim. Biophys. Acta 1787, 414-420.

Vega-Naredo, I., Cunha-Oliveira, T., Serafim, T.L., Sardao, V.A., Oliveira, P.J., 2015. Analysis of pro-apoptotic protein trafficking to and from mitochondria. Methods Mol. Biol. 1241, 163-180.

Vichai, V., Kirtikara, K., 2006. Sulforhodamine B colorimetric assay for cytotoxicity screening. Nat. Protoc. 1, 1112-1116.

Vousden, K.H., Ryan, K.M., 2009. p53 and metabolism. Nat. Rev. Cancer 9, 691-700.

Wei, S.N., Zhao, W.J., Zeng, X.J., Kang, Y.M., Du, J., Li, H.H., 2015. Microarray and coexpression network analysis of genes associated with acute doxorubicin cardiomyopathy in mice. Cardiovasc. Toxicol. 15, 377-393.

Wu, R., Smeele, K.M., Wyatt, E., Ichikawa, Y., Eerbeek, O., Sun, L., Chawla, K., Hollmann, M.W., Nagpal, V., Heikkinen, S., Laakso, M., Jujo, K., Wasserstrom, J.A., Zuurbier, C.J., Ardehali, H., 2011. Reduction in hexokinase II levels results in decreased cardiac function and altered remodeling after ischemia/reperfusion injury. Circ. Res. 108, 60-69.

Wu, R., Wyatt, E., Chawla, K., Tran, M., Ghanefar, M., Laakso, M., Epting, C.L., Ardehali, H., 2012. Hexokinase II knockdown results in exaggerated cardiac hypertrophy via increased ROS production. EMBO Mol. Med. 4, 633-646.

Zannini, L., Delia, D., Buscemi, G., 2014. CHK2 kinase in the DNA damage response and beyond. J. Mol. Cell Biol. 6, 442-457.

Zhang, S., Hulver, M.W., McMillan, R.P., Cline, M.A., Gilbert, E.R., 2014. The pivotal role of pyruvate dehydrogenase kinases in metabolic flexibility. Nutr. Metab. 11, 10.

Zhang, W., Zhang, S.L., Hu, X., Tam, K.Y., 2015. Targeting tumor metabolism for cancer treatment: is pyruvate dehydrogenase kinases (PDKs) a viable anticancer target? Int. J. Biol. Sci. 11, 1390-1400.

Zhao, G., Jeoung, N.H., Burgess, S.C., Rosaaen-Stowe, K.A., Inagaki, T., Latif, S., Shelton, J.M., McAnally, J., Bassel-Duby, R., Harris, R.A., Richardson, J.A., Kliewer, S.A., 2008. Overexpression of pyruvate dehydrogenase kinase 4 in heart perturbs metabolism and exacerbates calcineurin-induced cardiomyopathy. Am. J. Physiol. Heart Circ. Physiol. 294, H936-943.

Zhou, S., Starkov, A., Froberg, M.K., Leino, R.L., Wallace, K.B., 2001. Cumulative and irreversible cardiac mitochondrial dysfunction induced by doxorubicin. Cancer Res. 61, 771-777. 